[Aus dem Landesgesundheitsamt zu Schwerin.]

(Direktor: Geh. Obermedizinalrat Prof. Pfeiffer.)

\title{
Zur Influenzapandemie 1918
}

auf Grund bakteriologischer, pathologisch-anatomischer and epidemiologischer Beobachtungen.

Yon

Dr. F. Prein.

Nachdem uns das Jahr 1918 eine neue große Flutwelle der Influenza gebracht hat, sind zahlreiche Fachgelehrte bemüht gewesen, diese seit Jahrhunderten bekannte, im Umfang und der Sehnelligkeit ihrer pandemischen Ausbreitung einzig dastehende Seuche mit dem ganzen Rüstzeug moderner Wissenschaft zu erforschen. Eine außerordentlich umfangreiche neue Literatur ist seit dem vergangenen Jahre über die Influenza entstanden, so $\mathrm{da} B$ es überflüssig erscheint, den zahlreichen Veröffentlichungen noch eine weitere hinzuzufügen. Verfolgt man aber die Literatur genauer, so gelangt man zu der Erkenntnis, daß noch eine ganze Reihe von Fragen ihrer Klärung harrt und daß sogar die Kernfrage nach der Ätiologie der Influenza, die man seit 1892 durch die Entdeckung R. Pfeiffers längst geklärt glaubte, neuerdings wieder außerordentlich widerspruchsvoll beantwortet wird. Die Beurteilung der Ätiologie ist vielfach von einseitigen, bakteriologischen Gesichtspunkten aus erfolgt, weshalb auch die für die verschiedenen Anschauungen angeführten Argumente sehr häufig wenig beweiskräftig erscheinen. Meines Erachtens kann sich nur der ein selbständiges Urteil über die Ätiologie der Influenza bilden, der sowohl über eingehende bakteriologische und epidemiologische Beobachtungen als auch ganz besonders über eine genaue Kenntnis der Genese der bei der Influenza gefundenen krankhaften Prozesse auf Grund eigener makroskopischer und histologischer. Untersuchungen am gleichen Material verfügt. Da sich die Rolle der Mikroorganismen im menschlichen Körper allein nach den von ihnen ausgelösten Wirkungen bewerten läßt, so gilt es in erster Linie, die 
Beziehungen aufzuklären, die in den gleichen Organen zwischen etwa gefundenen Mikroorganismen und den vorhandenen pathologischen Vorgängen bestehen, wobei natürlich auch die klinischen Beobachtungen im einzelnen Falle in weitestgehender Weise Berïcksichtigung finden müssen. Von diesen Gesichtspunkten aus sind meine Untersuchungen geführt worden.

Bevor ich auf die Untersuchungen selbst eingehe, seien noch einige Worte über die Herkunft meines Materials gesagt. Für die bakteriologischen Untersuchungen wurde das im Landesgesundheitsamt größtenteils von mir selbst verarbeitete Material von Influenzakranken der Zivilbevölkerung Mecklenburgs und der Garnison Schwerin, sowie das Leichenmaterial von 40 in den Monaten Oktober bis Dezember von mir ausgeführten Sektionen verwertet. Die pathologisch-anatomischen Befunde wurden bei den Sektionen von $46 \mathrm{im}$ Schweriner Reservelazarett an Influenza Verstorbener erhoben. Obwohl während der Epidemiezeit im ganzen 138 Todesfälle an Influenza im Reservelazarett zu verzeichnen waren, habe ich nur eine verhältnismäßig geringe Zahl von Leichen seziert, da ich aus obigen Erwägungen heraus neben den Sektionen sowohl eine genaue bakteriologische als auch histologische Durcharbeitung des gewonnenen Materials in eigener Arbeit durchführen wollte, um aus eigener Anschauung die Grundlagen für die Beurteilung der Ätiologie der Influenza und der Genese der einzelnen anatomischen Veränderungen kennen zu lernen. Da die Leichen wahllos auf den Sektionstisch kamen und die für die sezierten Loichen ermittelten Durchschnittsziffern für Alter und Krankheitsdauer sich mit den für alle Todesfälle ermittelten Durehsehnittsziffern decken, so bin ich zu der Überzeugung gelangt, daß auch bei einer größeren Sektionstätigkeit in dem Ergebnis der Untersuchungen keine wesentlichen Versehiebungen erfolgt sein würden. Um einen Einblick in die epidemiologischen Eigentümlichkeiten der Influenza zu gewinnen, wurde an Hand genauer Aufzeichnungen ihr Verlauf bei den fast 8000 Kopf starken Truppenteilen der Garnison verfolgt, und das statistische Material der rund 11300 Mitglieder zählenden Ortskrankenkasse und des Standesamtes Sehwerin so weit wie möglich ausgewertet.

Was die Gliederung meiner Ausführungen betrifft, so habe ich nach Schilderung meiner bakteriologischen Untersuchungsergebnisse zunächst ein Bild der pathologisch-anatomisehen Veränderungen unter Betonung der Pathogenese, der Todesursachen und der Abgrenzung der ,reinen“ Influenza gegenüber ihren Komplikationen z. T. unter Verwertung der klinischen Erfahrungen zu entwerfen versucht, um dann auf die Epidemiologie näher einzugehen und schließlich zusammenfassend die Frage der Ätiologie, insbesondere die Bedeutung der Pfeiffersehen Bazillen kritiseh erörtert. 


\section{Bakteriologie.}

Zur Klärung der Bakteriologie der Influenza gelangte folgendes Material zur Verarbeitung: von Erkrankten 41 Sputumproben, 82 Pleuraexsudate, 44 Blutproben; an Leichenmaterial von 40 Sektionen in nahezu allen Fällen Blut aus dem Herzen, die Lungen, Milz, Nieren, Leber, außerdem 30mal Pleuraexsudat, 5mal eitriges Exsudat aus dem Perikard, 2mal eitriges Exsudat aus der Bauchhöhle, 3mal Tonsillenabszeßeiter, je 1mal Eiter aus einem perichondritischen AbszeB am Larynx und aus Abszessen im Mediastinum, 1mal pseudomembranöser Belag der Trachea. Die Ergebnisse der Untersuchungen bei den Angehörigen des Heeres und der Zivilbevölkerung stimmen für beide hier beobachteten Epidemien so vollständig überein, daß sie gemeinsam besprochen werden können.

Bei allen kulturellen Versuchen wurde das Material zunächst auf Hammelblutagar gebracht. Nur bei den mit Blut von Erkrankten angestellten Versuchen wurde das durch Venenpunktion gewonnene Blut außerdem zur Anreicherung in 2 Bouillonröhrchen gegeben und hiervon nach 1 bis 2tägiger Bebrütung mehrere Ösen auf Hammelblutagar übertragen. Der Blutagar wurde so hergestellt, daß gewöhnlichem, aus Fleischwasser bereitetem Nähragar nach Abkühlung auf etwa $50^{\circ} \mathrm{C} 21 / 2$ Prozent frisches, nicht defribiniertes durch Venenpunktion gewonnenes Hammelblut zugesetzt wurde. Dieser Nährboden hat sich mir für die Züchtung der Pfeifferschen Bazillen ausgezeichnet bewährt, während ein Versuch mit dem von Hundeshagen beschriebenen ,amerikanischen“ Nährboden, der im Prinzip mit dem Le vinthalschen Agar übereinstimmt, zum mindesten keine Vorteile erkennen ließ. Der Nachweis der Pfeifferschen Bazillen hat mir unter Verwendung des oben angegebenen Nährbodens keine besonderen Schwierigkeiten gemacht, wenn auch die Gewinnung der Reinkulturen zur Nachprïfung bei manchen Sputumproben und in vereinzelten Fällen auch bei den Lungen wegen des Vorhandenseins zahlreicher anderer Keime ziemlich zeitraubend war. Jedenfalls lehne ich für mein Material den wohl von Uhlenhuth zuerst ausgesprochenen und in der Literatur immer wiederkehrenden Einwand, daß eine mangelhafte Nährbodentechnik für die bei vielen Untersuchern negativen oder spärlichen Befunde an Pfeifferschen Bazillen verantwortlich zu machen sei, mit aller Entschiedenheit ab. Tch habe bereits im Anfange der ersten Epidemie Reinkulturen von Pfeiffersehen Bazillen erzielt und im Verlaufe der Epidemie sowohl durch Fortzüchtung isolierter Stämme als auch durch Neuzuichtung aus Untersuchungsmaterial die Brauchbarkeit meiner Nährböden nachzuprüfen vermocht. Außerdem habe ich, wie wohl alle Untersucher, stets auch mit Karbolfuchsin oder Methylgrïn-Pyronin 
gefärbte Ausstriche durchgemustert und meine kulturellen Ergebnisse am Sektionsmaterial selbst an den Schnittpräparaten kontrollieren und bestätigen können. Bei Besprechung der Ätiologie wird auf diese Punkte noch näher einzugehen sein. Als Pfeiffersche Bazillen wurden solche gramnegative, unbewegliche, schwer färbbare, feinste Stäbchen angesprochen, die auf Hammelblutagar in Reinkultur in zarten Kolonien, mit Staphylococcus aureus dagegen üppig, tautröpfchenartig wuchsen, dagegen nicht in Reinkultur auf Ascitesagar, hier dagegen ziemlich üppig in der Nähe von Kolonien von Staphylococcus aureus.

Sputumproben wurden nur in verhältnismäßig beschränkter Zahl zur Untersuchung gebracht, da ich wegen der Belastung durch die Sektionen nicht die Zeit übrig behalten habe, um größeres Material mit genügender Sorgfalt verarbeiten zu können. Die 41 untersuchten Proben stammten fast ausschließlieh von frischen Influenzafällen aus den ersten Krankheitstagen. Das zur Untersuchung verwandte Material mußte von den Kranken direkt in die Versandgefäße entleert wetden, um Verunreinigungen so gut wie möglich zu vermeiden. Die Verarbeitung erfolgte am Tage der Entleerung. Bei der Untersuchung wurde besonderer Wert auf den Nachweis der Pfeiffer schen Bazillen gelegt, die aber nur 6 mal oder in 141/2 Prozent der Fälle nachgewiesen werden konnten. In der großen Mehrzahl der Fälle wurden hämolytische Streptokokken, weniger Pneumokokken gefunden. Die Sputa waren in der Regel schleimig-eitrig und enthielten in den für Pfeiffersche Bazillen positiven Fällen diese Bakterien in mäßigen Mengen neben anderen Koimen. Nur 2mal waren sie reichlicher vorhanden, aber die Bilder erinnerten bei weitem nicht an die von R. Pfeiffer 1892 besehriebenen.

In den 82 durch Punktion gewonnenen Pleuraexsudaten wurden $69 \mathrm{mal}$ gleich 84 Prozent hämolytische Streptokokken gefunden, diese 64mal in Reinkultur, darunter 2mal Streptococeus mucosus. Neben den Streptokokken waren $2 \mathrm{mal}$ Pfeiffersehe Bazillen vorhanden. 11 mal gleich 13 Prozent fand sich Diplococcus lanceolatus, und zwar $8 \mathrm{mal}$ in Reinkultur, $2 \mathrm{mal}$ mit Pfeifferschen Bazillen, 1 mal mit Staphylococcus pyogenes aureus. Nur in je 1 Falle wurden Pfeiffersche Bazillen und Staphylococcus aureus in Reinkultur nachgewiesen. In den Pleuraexsudaten von Kranken waren demnach Pfeiffersche Bazillen in Reinkultur nur in 1.2 Prozent, insgesamt in 6 Prozent der Fälle vorhanden. Aus den Exsudaten, in denen färberisch die kleinen, gramnegativen Stäbchen nachgewiesen werden konnten, gelang auch mühelos die Kultur von Pfeifferschen Bazillen. Besonders in den streptokokkenhaltigen Exsudaten war die Zahl der Bakterien eine derart enorme, daß man am gefärbten Ausstrich vielfach den Eindruck gewann, als habe man eine dichte Bouillonreinkultur vor sich. 
In Blutproben von 44 Influenzakranken wurden 10 mal gleich $221 / 2$ Prozent hämolytische Streptokokken durch einmalige Untersuchung nachgewiesen. Alle Proben waren dureh Venenpunktion-entnommen, also vor Verunreinigung durch Hautsaprophyten geschützt. Die für die Blutuntersuchungen ausgewählten Kranken hatten sämtlich Lungenkomplikationen und zeigten septische Erscheinungen. Außer den Streptokokken waren keine Bakterien festzustellen. In einigen Fällen wurde noch Eiter aus metastatischen Abszessen bei Influenza untersucht und hämolytische Streptokokken gefunden mit Ausnahme eines Falles, in dem Pfeiffersche Bazillen in Reinkultur im Eiter vorhanden waren.

Fïr die im Anfang manchmal nicht leichte Differentialdiagnose von Typhus und Influenza wichtig ist die beobachtete Tatsache, daß das Blutserum Influenzakranker, die nicht gegen Typhus geimpft waren, in einem ziemlich hohen Prozentsatz eine Agglutinationsfähigkeit für Typhusbazillen bis zur Verdünnung 1:200, in wenigen Fällen auch bis zu 1:400 zeigte, während Paratyphusbazillen in der Verdünnung 1:50 stets unbeeinflußt blieben. Diese Befunde stehen in einem gewissen Gegensatz zu der Beobachtung von Mayer, der bei typhusschutzgeimpften Militärpersonen, bei denen er in der Regel Agglutinationswerte von 1:100 bis 1:200 gewohnt war, ein Sinken des Titers bis zur völligen Aufhebung der Agglutination im Verlauf der Influenzaerkrankung fand. Einige Male wurde Liquor cerebrospinalis mit der Diagnose „Meningismus bei Grippe" zur Untersuchung gebracht. Der Liquor war stets steril, Pleozytose nicht vorhanden, Phase I nur einmal ganz schwach positiv.

Besonders wertvoll für die Beurteilung dor Bakteriologie, Pathogenese, Klinik und Epidemiologie der Influenza haben sich mir die eingehend durchgeführten Untersuchungen des Leichenmaterials erwiesen, da ich hicrbei in jedem Einzelfalle selbst erhobene bakteriologische, pathologisch-anatomische and histologische Befunde miteinander und mit den klinischen Beobachtungen in Vergleich setzen konnte. Daß bei der Verarbeitung des zur bakteriologischen Untersuchung bestimmten Materials mit peinlichster Vorsicht auf Ausschaltung aller Fehlerquellen Bedacht genommen wurde, ist zwar selbstverständlich, sei aber noch besonders betont.

Im Blut, in den Organen und entzündlichen Produkten derselben Leiche wurden in der Regel die gleichen pathogenen Keime nachgewiesen, und zwar mit Ausnahme der Lungen meist nur eine Art und diese in Reinkultur. Mischinfektionen waren als Allgemeininfektion sehr selten. Nur in 2 von 40 untersuchten Fällen wurde neben Streptokokken in einzelnen Organen und im Pleuraexsudat auch Staphylococcus aureus gefunden, doch bemerkens- 
werterweise im Herzblut auch hier nur Streptokoklen. Wie nach den Untersuchungen am Krankenmaterial zu erwarten war, beherrschen auch im Sektionsmaterial Streptokokken fast ausschließlich das bakteriologisehe Bild. Während bei 40 untersuchten Leichen nur 1 mal Diplococcus lanceolatus und 2mal Staphylococcus aureus als alleinige Erreger im Blut und fast allen Organen gefunden wurden, hatten Streptokokken in 37 Fällen also in 90 Prozent zu Bakteriämie bzw. Sepsis geführt. Ihre Zahl war außerordentlich sehwankend, doch war nicht zu verkennen, daß sie im Vergleich zum Krankenblut im allgemeinen sehr viel reichlicher vorhanden waren. In direkten Ausstrichen von mehreren Ösen Venenblut von Kranken auf Blutagar gingen nur in 2 von 10 Fällen, die nach Bouillonanreicherung positiv waren, vereinzelte Streptokokkenkolonien an, während direkte Ausstriche von ungefähr der gleichen Menge Leichenblut stets positive Resultate ergaben. In zahlreichen Fällen wuchs hier sogar ein dichter, zusammenhängender Belag. Vergleicht man weiter das Ergebnis der Blutuntersuchurgen bei den gleichen Personen kurz vor und nach dem Tode, so ergibt sich mit zwingender Notwendigkeit die Tatsache, daß eine beträchtliche Vermehrung der Bakierien im Blut erst in der Agonie stattgefunden hatte. Denn bei 4 letal endigenden Fällen kor̀̀ten etwa 24 Stunden vor dem Tode im strömenden Blut Streptokokken auch durch Bouillonanreicherung nicht, in weiteren 2 Fällen nur sehr spärlich nachgewiesen werden, während in diesen Fällen ein bis wenige Stunden nach dem Tode schon im direkten Ausstrich auf Blutagar rehr oder weniger zahlreiche Streptokokkenkolonien angingen. Pfeiffersche Bazillen konnten weder im Blut noch in den inneren Organen mit Ausnahme der Lungen und Pleuraexsudate nachgewiesen werden. Einmal glaubte ich aus einer Blutbouillonanreicherung Pfeiffersche Bazillen gezüchtet zu haben, da jeh von Ausstrichen der Anreicherung auf Blutplatten eine Rein. kultur eines Stäbchens erzielte, das in bezug auf Aussehen der Kolonien und morphologische Kennzeichen ganz den von Pfeiffer verlangten Anforderungen entsprach. Bei der Nachprüfung stellte sich aber heraus, daß die Stäbchen grampositiv waren. Ich erwähne dies, um zu zeigen, wie vorsichtrg man mit der Diagnose "Influenzabazillus" sein muß. Auffallend häufig, in $1 / 3$ der untersuchten Fälle erwies sich die Milz auch in der Kultur ais steril, auch wenn im Herzblut zablreiche Streptokokken gefunden wurden. Da sich Nieren und Leber nur ganz vereinzelt als steril erwiesen, scheinen in der Milz besonders starke Abwebrkräfte des Organismus konzentriert zu sein. Eiter aus den Tonsillarabszessen, aus perichondritischem Abszeß im Larynx und Mediastinalabszessen, die Exsudate aus dem Perikard und def Bauchhöhle enthielten stets Streptokokken, nie Pfeiffersche Bazillen. In einem Falle wurde aus einem umfangreichen, zusammenhängenden, 
pseudomembranösen Belag der Trachea Staphylococcus aureus in Reinkultur gezïchtet. Er wurde bei dieser Leiche als alleiniger Erreger im Blut, in der Lunge und den inneren Organen angetroffen.

Zu erwähnen bleiben noch die Ergebnisse der Untersuchungen von Lungen und Pleuraexsudaten. Für die Entnahme des Untersuchungsmaterials aus den Lungen wurden neben besonders hochgradig erkrankten Stellen auch makroskopisch anscheinend erst im Beginn der Krankheitsprozesse sich befindende Partien ausgewählt, um nicht Keime zu übersehen, die durch das Überwuchern durch die pyogenen Kokken verdrängt waren. Stets wurden in der Lunge diejenigen Bakterien gefunden, die auch zur Allgemeininfektion geführt hatten, $d$. h. also nach dem oben Gesagten fast ausschließlich Streptokokken, nur 1 mal Diplococcus lanceolatus und $2 \mathrm{mal}$ Staphylococcus aureus in Reinkultur. Neben den Streptokokken waren nur 4mal Pfeiffersche Bazillen, 1mal Pneumokokken, 1mal Staphylokokken vertreten. In Reinkultur wurden Pfeiffersehe Bazillen nie angetroffen. Die Kokken waren meist außerordentlich reichlich an Zahl und nur selten von saprophytischen Koimen begleitet. Auch die Pfeifferschen Bazillen waren in den wenigen Fällen, wo sie vorhanden waren, ziemlich zahlreich und sowohl in gefärbten Ausstrichon als auch durch Kultur leicht nachzuweisen. In zwei der für Pfeiffersche Bazillen posiciven Fälle waren diese mit den Streptokokken auch ins Pleuraexsudat übergegangen. In einem dieser Fälle wurden sie nur linksseitig in Lunge und Pleuraexsudat gefunden, während rechtsseitig nur Streptokokken zur Entwicklung kamen. Die Pfeifferschen Bazillen hatten sich in diesem Falle gerade an der Seite angesiedelt bzw. am längsten gehalten, an der außerordentlich umfangreiche eitrige Einschmelzungen von Lungengewebe erfolgt waren, während an der Seite, wo sich erst scharfbegrenzte, kleine, bronchopneumonische Herde gebildet hatten, vergeblich nach ihnen gefahndet wurde. Auch in einem anderen Falle waren die Pfeifferschen Bazillen nur einseitig in den Lungen vorhanden. Der einseitig negative Befund kann nicht durch Mängel der Nährböden seine Erklärung finden, da das Untersuchungsmaterial in jedem Falle aus den beiden Lungen in gleicher Methodik auf dieselbe Blutplatte ausgestrichen war und die Begleitbakterien dieselben waren. Ich habe nicht die Erfahrung gemacht, daß die Pfeifferschen Bazillen gerade bei den ganz frischen Krankheitsprozessen und nur in den orsten Krankheitstagen zu finden sind, denn gerade die wenigen Fälle, in denen sie bei meinem Sektionsmaterial vorhanden waren, betrafen vorgeschrittene Lungenveränderungen mit einer Krankheitsdauer von 11, 7, 19 und 9 Tagen bei einer durehschnittlichen Krankheitsdauer von $8 \frac{1}{2}$ Tagen für alle Todesfälle. Die bakteriologische Untersuchung der pleuritischen Exsudate vom Leichen- 
material gab ein ähnliches Bild wie beim Krankenmaterial. Von 32 Exsudaten enthielten 30 Streptokokken, je 1 Pneumokokken bzw. Staphylokokken in Rinkultur. Neben den Streptokokken waren 2 mal Pfeiffersche Bazillen, 1mal Staphylococcus aureus vorhanden.

Betrachtet man bei dem gesamten, bakteriologisch untersuchten Material zusammenfassend das Vorkommen der Pfeifferschen Bazillen, so ergeben sich folgende Werte:

in 41 Sputumproben von Kranken $6 \mathrm{mal}=141 / 2$ Prozent

"82 Pleurasxsudaten ". " $5,=6$,"

"38 Lungen von Influenzaleichen $4,=10^{1} / 2$,

"32 Pleuraexsudaten von ", 2 " $=6$,

Die Prozentzahlen stimmen für Kranken- und Leichenmaterial so auffallend überein, daß der Nachweis der Pfeifferschen Bazillen keinen großen Schwankungen unterworfen gewesen sein kann und sprechen auch gegen die allgemeine Gültigkeit der Behauptung, daß sie beim Material von Kranken sehv viel häufiger zu finden seien als im Leichenmaterial.

Zum Schluß seien noch einige kurze Worte über die Morphologic und Biologie der gefundenen Streptokokken gestattet. Zunächst isi zu betonen, daß die gefundenen Streptokokken morphologisch wie biologisch keineswegs einheitlich waren, sondern außerordentlich viele Unterarten und Varianten erkennen ließen, wie das ja für die pyogenen Streptokokken seit langem bckannt ist. Eine wirklich befriedigende Einteilung nach ihren pathogenen und biologischen Eigenschaften ist bisher nicht gelungen und wird infolge ihrer großen Variabilität vielleicht auch ganz unmöglich sein. Das Schema, das Lehmann und Neumann zum Teil in Anlehnung an Schottmüller von den Streptokokken geben, nennt an menschenpathogenen Streptokokkenarten longus, mitior, mucosus und lanceolatus. Die genannten Autoren botonen aber ausdriicklich, daß schon dieses Schema zahlreiche Übergangsformen ignoriert. Diese Erfahrung kann jch vollauf bestätigen. Weitaus die meisten der von mir isolierten Stämme fallen unter die Gruppe von Streptococeus longus mit starker Hämolysinbildung, langer Kettenbildung in Bouillon und kheinen, zarten Kolonien auf Blutagar mit körniger, trockener Oberfläche. In bezug auf Länge der Ketten und Feinheit des Kornes bestanden bemerkenswerte Unterschiede. Ein wesentlich geringerer Teil der isolierten Stämme gehörte zur Gruppe des Streptococcus lanceolatus mit seinen bekannten, ziemlich konstanten morphologischen und biologischen Eigensehaften. Nur ganz vereinzelt, $2 \mathrm{mal}$ aus Pleuraexsudaten von Kranken, 1 mal aus Blut und Organen einer Leiche wurde neben Streptococcus longus auch Streptococcus mucosus gefunden. In einem Falle wurde aus einer 
Lunge Streptococcus mitior gezüchtet. Außer diesen typischen Vertretern der 4 Unterarten kamen vielfach Übergainge vor. So wurde ziemlich oft allein oder neben den bereits erwähnten ein Stamm gezüchtet, der bei starker Hämolysin- und langer Kettenbildung in üppigen, glasigen, feuchtglänzenden Kolonien ähnlich Mucosus wuchs, aber keinerlei Kapselbildung erkennen ließ. Sein Korn war sehr fein, die Grundform der Ketten, wie übrigens bei allen von mir beobachteten Stämmen, die Diploform. Ein anderer Stamm. nahm eine Mittelstellung zwischen Streptococcus mitior und lanceolatus ein. Er zeigte bei für Streptococcus mitior typischen Wachstumseigenschaften ein ausgesprochen lanzettliches Korn. Geringes Säurebildungsvermögen auf Dextrose, Maltose und Lävulose- war allen Stämmen mit Ausnahme von Streptococcus lanceolatus eigen.

$\mathrm{Daß}$ die bei der Influenza vorkommenden Streptokokken nichts anderes als die gewöhn'ichen pyogenen Kokken von hoher Virulenz sind, geht nicht nur aus dem Ergebnis dieser Nachprüfung ihrer morphologischen und biologischen Eigensehaften hervor, sondern wird auch praktisch durch folgende Erfahrung bestäiigt. Da die bei den Sektionen beteiligten Personen keine Schutzhandschuhe trugen, so kam es bei dreien, die in intensivere Beruihrung mit den inneren Organen der Influenzaleichen kamen, zur Bildung zahlreicher Aknepusteln an den vorher stets gesunden Händen und Unterarmen, die an pathogenen Keimen nur Streptokokken enthielten. Auffallend war hierbei, da $\mathrm{h}$ bei der Sektion akquirierte kleine Risse und Wunden stets vollkommen reizlos abheilten, während sich in den Haarbalgdrüsen die Streptokokken festsetzten und von hier aus ihre pathogenen Wirkungen entfalteten. Während ich selbst durch Alkoholverbände wäbrend der Nacht die entzündlichen Erscheinungen in geringen Grenzen halten konnte, kam es bei einem Feldunterarzt und einem Krankenwärter zu gefährlicher Zellgewebsentzündung an der Mrttelhand mit Lymphangitis bis zur Achsel, die breite Inzisionen erforderlich machte.

Verfolgt man die einschlägige Literatur der vorjährigen Pandomie, so ergibt sich in bezug auf die Zusammensetzung und die Bedeutung der bei der Influenza gefundenen Begleitflora weitgehende Übereinstimmung, wenn man zunächst die Pfeifferschen Bazillen aus der Betrachtung ausscheiden läßt. Wenn im Anfange der Pandemie vereinzelt Neigung bestanden hat, die von den meisten Untersuchern vorwiegend gefundenen Streptokokken als spezifische Erreger anzusprechen, so kann es wohl nach meinen eigenen Erfahrungen und nach den zahlreichen Veröffentlichungen jetzt keinem Zweifel mehr unterliegen, daß neben den Pneumo- und Staphylokoklken auch die Streptokokken lediglich eine Rolle als Sekundär- oder Misch- 
infektionserreger bei der Influenza spielen, so daß sich ein näheres Eingehen auf die Literatur in dieser Beziehung erübrigt. Nur auf einen Punkt möchte ich noch hinweisen. Während die größere Zahl der Untersucher vorwiegend Streptokokken gefunden hat, berichtet eine nicht unbeträchtliche Änzahl über ein stärkeres Hervortreten der Pneumokokken, z. T. auch der Staphylokokken. Besonders die neben den Streptokokken in den Lungen gefundenen Keime sind starken lokalen Verschiedenheiten nach Zahl und Art unterworfen gewesen. Die Feststellung dieser lokalen Unterschiede im bakteriologischen Bild ist deshalb von Wichtigkeit, da sie uns weiter unten auch die lokalen Abweichungen im pathologisch-anatomischen Bild werden erklären müssen. Auf die Rolle der Influenzabazillen und auf die serologischen und anderen ätiologischen Forschungen werde ich erst nach Darlegung der pathologisch-anatomischen und epidemiologischen Untersuchungen näher eingehen, da diese für die Beurteilung jencr Fragen von ausschlaggebender Bedeutung sind.

\section{Pathologische Anatomie.}

Wie bereits eingangs erwähnt wurde, stützen sich meine pathologischanatomischen Befunde auf die Erfahrungen bei 46 Sektionen, die alle Angehörige des Heeres oder Kriegsgefangene betrafen. Hiervon entfielen 6 Sektionen auf die Juliepidemie, während die übrigen 40 in der Zeit von Anfang Oktober bis Mitte Dezember vorgenommen wurden. Um einen tieferen und zweifelsfreieren Einblick in die Gewebsveränderungen und ihre Genese zu gewinnen, als es bei makroskopischer Betrachtung möglich ist, habe ich von histologischen Untersuchungen weitgehenden Gebrauch gemacht. Im ganzen wurden über 400 histologische Präparate einer eingehenden Durchmusterung unterzogen. Für die Bakterienfärbung in Schnitten hat sich mir auch für die Pfeifferschen Bazillen nach Fixierung in Formol-Müller die Methylgrün-Pyroninfärbung nach Pappenheim bei einer Färbezeit von 5 Minuten unter kräftigem Erwärmen und kurzem Entwässern in absolutem Alkohol bestens bewährt. Gram - oder andere Spezialfärbungen waren überflüssig, da ich ja das ganze Sektionsmaterial selbst bereits kulturell und in gefärbten Ausstrichen auf seinen Bakteriengehalt geprüft hatte. Dic bakteriologischen Untersuchungen der Schnitte hatten also nur noch die Beziehungen der schon festgestellten Bakterien zum Gewebe aufzuklären.

Die größere Zahl der Leichen (27) waren kräftige, muskulöse Gestalten in gutem Ernährungszustande; 8 waren mittelkräftiger Statur, aber ausreichend ernährt; 11 zeigten grazilen Knochenbau und mehr oder weniger 
stark reduzierten Ernährungszustand. Bei der äußeren Besichtigung fiel in 8 Fällen geringe bis mäßige ikterische Verfärbung der Haut und der Sklera auf. In 3 von diesen Fällen war auch klinisch schon ausgesprochener Ikterus festgestellt worden. In der Literatur finde ich darüber wenig Angaben. Oberndorfer, Marchand und Busse berichteten von Ikterus bei Sektionsmaterial, Becher, Hoppe-Seyler und Brasch aus klinischen Beobachtungen. Ferpes labialis wurde nur vereinzelt gesehen. In 2 Fällen bestand eine ausgedehnte Eruption kleiner, hirsekorngroßer Bläsehen mit klarserösem Inhalt an der Bauchhaut und der Leistenb $\mathrm{u}_{t} \mathbf{e}$ bzw. der Achselgegend. Einmal wurden vorwiegend an der Haut der Brust zahlreiche kleine Roseolen gefunden.' Histologisch besteht an den Stellen der Roseolen ein herdförmiger Blutaustritt per Diapedesin ins Korium ohne besondere entzündliche Erscheinungen. Bakterien konnten hier nicht nachgewiesen werden. Des öftern, besonders bei den schnell letal verlaufenen Fällen, waren Mundund Nasenöffnungen mit blutigseröser, schaumiger Flüssigkeit angefüllt, die sich in einzelnen Fällen bei nur leichtem Druck auf den Thorax in größerer Menge aus diesen Öffnungen ergoß. Die Rumpfmuskulatur bot im allgemeinen wenig Auffallendes; nur in einigen Fällen wurden ausgesprochene Veränderungen im Sinne der wachsartigen Degeneration gefunden. Nur einmal war diese hochgradig und hatte beiderseits zur Zerreißung des Rektus abdominis mit Hämatom dicht unterhalb des Nabels geführt.

Von den Körperhöhlen zeigte die Schädelhöhle die geringsten pathologischen Befunde. Außer einer stets zu findenden starken Füllung der venösen Gefäße der Pia und der Hirnsubstanz bestand in einem Falle ein mäßiges Ödem der Meningen, in einem anderen multiple, punktförmige Blutaustritte in der weißen Hirnsubstanż und im Knie des Balkens. Besonders auffällige Erscheinungen von seiten des Zentralnervensystems wurden klinisch in diesen Fällen nicht beobachtet. Von anderen Untersuchern wird über schwerere Veränderungen an Meningen und Hirnsubstanz berichtet. So fand Schmorl Hirnpurpura in 30 Prozent seiner Fälle; Hannemann, Dietrich, Goldschmid, Borst, Berblinger, Busse sahen eitrige Meningitiden infolge bakterieller Infektion z. T. mit Pfeiffer schen Bazillen, Siegmund eine hämorrhagisch-eitrige Encephalitis beider Schläfenlappen, Goldschmid eine Sinusthrombose. In einzelnen Fällen ist es durch Mobilisierung von Tuberkelbazillen aus alten Herden durch die Influenza zu tuberkulöser Meningitis gekommen, wovon $u$. a. Borst berichtet.

Schwere und in gewissem Sinne für Influenza charakteristische anatomische Veränderungen wurden in der Brusthöhle, speziell im Respirationstraktus vorgefunden. Da klinisch Koryza bei der hiesigen Epidemie nur 
sehr selten in Erscheinung trat, wurde der Betrachtung des Nasenraumes und seiner Nebenhöhlen keine Bedeutung beigelegt. Daß dieselben weitgehende Entzündungserscheinungen aufweisen können, geht aus den Mitteilungen von E. Fraenkel hervor, der bei 60 untersuchten Nebenhöhlen in 75 Prozent hämorrhagische oder eitrige Entzündungen als Folge der Influenza feststellte. Die Gaumentonsillen waren in einem kleinen Teil der Fälle entzündlich geschwollen und wiesen 3mal Abszesse ataf, die an pathogenen Keimen zahlreiche Streptokokkon enthielten. Die Zunge war in der Hälfte der Fälle schmutzigweiß belegt, selten borkig und rissig. Der Pharynx zeigte fast durehweg eine dunkelblaurote Verfärbung, die sich am Arcus pharyngo-palatinus bzw. an der Zungenwurzel meist scharf nach vorn absetzte. Auf diese scharfe Grenze zwischen dunkelgerötetem weichem und nicht gerötetem hartem Gaumen weisen auf Grund klinischer Beobachtungen auch Lämpe und Alexander hin. Letzterer erklärt dies für einen typischen, bei allen Kranken beobachteten Befund. In 10 Prozent meiner Fälle bestand eine ödematöse Schwellung der aryepiglottischen Falten und der Mukosa im Vestibulum laryngis. Nur in einem dieser Fälle war gleichzeitig ein eigentliches Glottisödem feststellbar, das nach Würdigung des klinischen Verlaufs und des Sektionsbefundes als direkte Todesursache angesprochen werden mußte. Die Ödeme waren mit Ausnahme eines Falles, in dem die Entstehung unklar blieb, auf eitrige Entzündung in der Umgebung, u. a. der Gaumentonsillen zurückzuführen.

Larynx, Trachea und die großen Bronchien zeigten im allgemeinen die gleichen pathologischen Veränderungen in wechselnder Intensität. Die Schleimhau war hier fast stets intensiv gerötet und etwas körnig geschwollen, bot also makroskopisch das Bild der katarrhalischen Entzïndung. Die entzïndlichen Veränderungen begannen im Larynx vielfach erst unterhalb der Stimmbänder und erreichten, nach unten zunehmend, ihren Höhepunkt in der unteren Trachea und an der Bifurkation. Diese hochgradige Tracheitis mit eigentümlich dunkler, satter Rötung der Mukosa ist der einzige, regelmäßig wiederkehrende Befund, den man der Wirkung des spezifischen Influenzavirus zuschreiben kann, da fast alle anderen pathologisehen Veränderungen, wie wir noch sehen werden, der Misch- bzw. Sekundärinfektion zur Last zu legen sind: Histologisch präsentiert sich die Schleimhaut der Trachea in diesen reinen Fällen folgendermaßen: Schon nach 1tägiger Krankheitsdauer ist das Flimmerepithel fast restlos abgestoßen, während die Basalmembran in ganzem Zuge tadellos erhalten bleibt. In der Submukosa findet man stellenweise geringe bis mäßige Rundzelleninfiltration und eine hochgradige Hyperämie. Trotz langen Suchens in speziell gefärbten Sehnitten konnten weder an der Oberfläche der Schleimhaut noch im Gewebe irgend- 
welche Mikroorganismen nachgewiesen werden, auch nicht in den Fällen, in denen die Lungen zahlreiche Pfeiffersche Bazillen enthielten. Nur in den kleinen Gefäßen steckten dichte Kokkenhaufen in den Fällen, in denen sie auch in Schnitten der innern Organe gefunden wurden. Doch waren sie von der Gefäßwand fest umschlossen, und das Gewebe in der Umgebung zeigte keine Reizerscheinungen.

Ein ganz anderes Bild boten Larynx und Trachea in den_wenigen Fällen, in denen sich in der Schleimhaut die pyogenen Kokken angesiedelt hatten. In den 4 Fällen, in denen Streptokokken nachgewiesen wurden, bestanden neben flachen, oberflächlichen Ulzera fleckweise dünne, mehr flockige Beläge von schmutziggelber Farbe im Larynx und der Trachea, während die Staphylokokken in dem einzigen Falle, bei dem sie in der Trachea angetroffen wurden, eine zusammenhängende, tiefgreifende, nekrotisierende Entzündung der Schleimhaut bis zu den großen Bronchien hinab hervorgerufen hatten, die sich histologisch als eine Nekrose der oberen Schleimhautschichten einschlieblich der Basalmembran und den oberen Schichten der Submukosa mit starker Infiltration polymorphkerniger Leukozyten und hochgradiger Hyperämie darstellt. In den Belägen wuchert ein dichter Rasen von Streptobzw. Staphylokokken. Die Streptokokken haben sich anscheinend zunächst in den Ausführungsgängen der Schleimdrüsen und in den Drüsen. selbst angesiedelt und sich erst von hier aus in der Schleimhaut weiter ausgebreitet, denn in Schnitten aus Partien, die noch keine pseudomembranöse Entzündung erkennen lassen, findet man sie lediglich an diesen Stellen, wo sie dann aber schon eine dichte Anhäufung von Rundzellen und polymorphkernigen Leukozyten veranlaßt haben. Von hier aus ist es auch in einem Falle zu einer phlegmonösen Entzündung im rechten Taschenband mit umfangreicher eitriger Einschmelzung des dem Knorpel anliegenden Gewebes durch Streptokokken gekommen. Stenosenerscheinungen waren klinisch in diesem Falle nicht aufgefallen. Die Art der Ansiedlung der Streptokokken in den Schleimdriusen der Trachea bildet ein Analogon zu ihrer Ansiedlung in den Haarbalgdrüsen der Haut, auf die ich weiter oben bereits hingewiesen habe. Der Inhalt der Trachea und großen Bronchien bestand vielfach aus schleimig-eitrigem Sekret, in einem Teil der Fälle aus blutigseröser, schaumiger Flüssigkeit.

Die Angaben in der Literatur decken sich im allgemeinen, soweit sie die anatomischen Veränderungen betreffen, mit meinen Beobachtungen. Von allen Untersuchern wird übereinstimmend auf die in den akuten Fällen stets vorhandene Tracheabronchitis hingewiesen, wobei allerdings die nekrotisierenden Formen lokal an Zahl sehr verschieden gewesen sind. Während 
1. a. Hübschmann, Borst, Hannemann nur ganz vereinzelte Fälle von nekrotisierender Entzündung gesehen haben, fand sie S. Meyer unter 8 Fällen 6mal, Goldschmid bei 85 Sektionen 41mal. Die Angaben der Pathologen über eine Beteiligung der Rachenschleimhaut sind spärlich. Borst, Siegmund, Busse fanden häufig eine katarrhalische Entzïndung derselben, ersterer wie auch Goldschmid in einem Fall eine pseudomembranöse Entzündung. Hannemann, Dietrich berichten dagegen über keine oder nur geringe Beteiligung des Nasenrachenraumes, während die meisten anderen Untersueher überhaupt keine besonderen Befunde hierüber mitteilen. Meine Beobachtungen über eine fast regelmäßige Pharyngitis werden aber durch die Kliniker vollauf bestätigt, die fast ausnahmslos eine stärkere Rötung besonders der hinteren Rachenwand und der Gaumenbögen gesehen haben und diesen Befund zum Teil sogar als charakteristisch für die Influenza bezeichnen. Die Tonsillen fanden Dietrich und Goldschmid stets reaktionslos, während sie bei dem Material von Borst oft entzündlich serös durchtränkt waren und $2 \mathrm{mal}$ Abszesse aufwiesen. Oberndorfer berichtet über „eine fast regelmäßig vorhandene mächtige Ausbildung der lymphatischen Apparate des Zungengrundes und Rachenringes, die nicht nur Folge entzïndlicher Schwellung, sondern zweifellos schon vorher bestandener Hyperplasie ist". Da er auch fast stets einen parenchymreichen, wenig verkleinerten Thymus, große Milz- und Darmfollikel gesehen hat, nimmt er an, daß bei der Influenza vor allem Lymphatiker dem Tode verfallen seien. Diesen Beobachtungen gegenüber. wird von allen späteren Untersuchern betont, daß ein auffälliges Hervortreten des Status thymo-lymphaticus nicht vorhanden gewesen ist. Auch bei meinem Material wurden derartige Befunde nicht erhoben.

Erhöhtes Interesse beanspruchen die anatomischen Veränderungen der Lungen einschließlich der kleinen Bronchien und der Pleura. Verfolgt man zunächst an meinem Material weiter das Verhalten der Bronchien, so hat man schon makroskopisch den Eindruck, daß die mittleren Bronchien weniger starke Entzündungserscheinungen darbieten als die großen Bronehialäste und die Trachea, daß hingegen die feineren Bronchien wieder lebhafter an den entzündlichen Vorgängen beteiligt sein müssen, da sie schon makroskopisch feststellbar in etwa 40 Prozent der Fälle in wechselnder Ausdehnung mit rahmigem, gelblichem Eiter angefüllt sind. Den stärksten Anteil an den entzündlichen Prozessen nehmen aber die Bronchiolen für sieh in Anspruch. Die stets durchgeführten histologischen Untersuchungen decken hier ohne Ausnahme auch in den ganz frischen Fällen, die innerhalb der ersten Krankheitstage ad exitum gekommen sind, allerschwerste citrige 
Entzïndung auf, die fast stets mit einer vollkommenen eitrigen Einschmelzung der Wandungen einhergeht, so dab in großen Lungenabschnitten die Bronchiolen total zerstört werden und in ihrer Funktion ausfallen. In den frisch erkrankten Lungenpartien hat diese schwere, eitrige Entzündung ihren Sitz in den feinsten Bronchien und Bronchiolen unter 0.3 mm Durchmesser. Sie tritt von allen eitrigen Entzündungen im Verlauf der Influenza zuerst auf, denn in den frischen Fällen bieten vielfach weder das Lungendarenchym noch die Trachea und Bronchien über $0.3 \mathrm{~mm}$ irgendwelche eitrige Entzündungserscheinungen dar. In den letzteren ist hier manchmal kaum eine Epithelschädigung zu erkennen, wenn die feinen Bronehiolen bereits der Einschmelzung zum Opfer gefallen sind. Findet man also in der Trachea oder den großen Bronchien die weiter oben beschriebenen nekrotisierenden bzw. ulzerösen Entzündungen, so müssen wir diese als durch kokkenhaltiges Sputum aszendierend entstanden bezeichnen. Im Bronchioleneiter trifft man stets die aus dem bakteriologischen Teil bekannten Kokken an, meistin enormer Zahl. In den Fällen, in denen kulturell P feiffe rsche Bazillen in den Lungen nachgewiesen waren, finden wir diese ganz überwiegend im eitrigen Inhalt der Bronchiolen. Regenerationsvorgänge an den Bronchiolen treten erst im späteren Krankheitsverlauf oin. Deutliche Bronchiolenneubildung wurde nur in Fällen gefunden, die nach über 20tägigem Krankenlager verstorben waren. Die eitrige Bronchiolitis entsteht zweifellos erst auf dem Boden der spezifischen Influenzainfelation derart, daß in den Bronchiolen besonders günstige Wachstumsbedingungen für die beschriebenen Mikroben geschaffen werden. $O b$ es sich hierbei um eine Virulenzsteigerung der Eitererreger durch Symbiose mit dem Influenzavirus oder um eine lokale, den Eitererregern besonders zusagende Gewebsschädigung handelt, dürfte schwer zu entscheiden sein. Wir haben hier sicher ähnliche Wechselwirkungen zwischen spezifischem Virus und pyogenen Bakterien vor uns, wie wir sie bereits von anderen Elkrankungen, z. B. Scharlach und Masern her kennen. Dab die Bronchiolitis sich meist in so ausgedehnter Weise in den Lungen verbreitet, crklärt sich zwanglos dadurch, $\mathrm{da} B$ die spezifische Influenzainfektion den Bronchialbaum in ganzer Ausdehnung befällt und damit in allen Bronchiolen einen locus minoris resistentiae für die Eitererreger sehafft. Findet nun auch nur an einer kleinen, umschriebenen Stelle in den Bronchiolen eine Infektion mit den pyogenen Bakterien statt, so tritt hier eine schnelle Vermehrung derselben ein und durch Husten und Aspiration der von dieser Stelle aufgehusteten Keime werden in kürzester Zeit zahlreiche Bronchiolen infiziert. Zur Erklärung der immer beiderseitigen, großen Ausdehnung der eitrigen Bronchiolitis ist also die Annahme einer besonders massigen Infektion mit den sekundären 
Eitererregern nicht erforderlich. Ich verweise hier noch ausdrücklich auf die grundsätzlich verschiedene Art der Entzündung in der Trachea und den großen Bronchien einerseits und den Bronchiolen andererseits. Dort in der Regel eine einfache katarrhalische Entzündung mit Rundzelleninfiltration ohne Beteiligung von Bakterien, hier die eitrige Entziundung stärksten Grades mit intensivster Leukozyteninfiltration durch bakterielle Infektion. $\mathrm{DaB}$ diese in allen Influenzafällen, die zur Sektion gelangten, bestehende ausgedehnte Bronchiolitis nicht ohne schwerwiegendem Einfluß auf das Lungenparenchym bleiben kann, ist zu erwarten. Tatsächlich lassen sich alle die vielseitigen pathologischen Befunde, soweit sie nicht als unmittelbare Wirkung des spezifischen Influenzavirus aufzufassen sind, letaten Endes auf diese eine Basis zurückfübren.

Die außerordentlich bedeutsame Rolle, die die eitrige Bronchiolitis in der Genese der zahlreichẹn Komplikationen der Influenza spielt, hat in der Literatur vielfach nicht genügende Beachtung gefunden. Wenn auch die meisten Untersucher der Bronchiolitis mebr oder weniger ausführlich Erwähnung tun, so wird die Abhängigkeit der noch zu besprechenden Komplikationen von der.eitrigen Entzündung der Bronchiolen im allgemeinen nicht scharf genug hervorgehoben. Besonders bei der Darstellung der Lungenveränderungen gewinnt man vielfach den Eindruck, daß die einzelnen, gleichzeitig nebeneinander bestehenden, in ihrer Art so sehr verschiedenen Prozesse nicht scharf genug voneinander getrennt werden. So kommt es denn auch, daß bei der Abgrenzung des Bildes der ,reinen“ Influenza gegen ihre Komplikationen, soweit überhaupt auf diese Frage eingegangen wird, meist irrtümliche Auffassungen bestehen, wie weiter unten noch zu beweisen sein wird. Eine besondere Würdigung der Bronchiolitis find ich u. a. besonders bei Dietrich, Borst, Berblinger und Siegmund.

Unmittclbare Wirkungen der eitrigen Bronchiolitis sind Verstopfungsatelektasen, kollaterales, entzündliches Ödem, eitrige Bronchopneumonien, Lymphangitis und Bakteriämie bzw. Sepsis. Die Kollapsatelektasen entstehen durch Verlegung der Bronchiolenlumina mit Eiter und durch Resorption der noch in den zugehörigen Lungenpartien enthaltenen Luft. Die Atelektasen werden in der Regel nicht mehr vorgefunden, da durch die intensiven Entzündungsprozesse an den Bronchiolen schnell ein entzündliches Ödem zur Entwicklung kommt, wodurch die kollabierten Lungenpartien wieder stark aufquellen und makroskopisch das Bild der Splenisation mit dunkelrotbrauner, glatter, sehr reichlich blutigseröse Flüssigkeit absondernder Schnittfläche bieten. Auch in nicht atelektischen Abschnitten ist häufig ein ausgesprochenes Ödem im Anschluß an die Bronchiolitis vor- 
handen. Diese Prozesse sind meist in einzelnen Lappen besonders ausgeprägt, wodurch diese dann außerordentlich voluminös werden bei stark herabgesetztem Luftgehalt und erhöhter Konsistenz. Splenisation und Ödem nehmen nach meinen Beobachtungen einen breiten Raum bei den Lungenveränderungen ein und sind vor allem in den Frühtodesfällen ganz besonders hochgradig. Von einzelnon anderen Untersuchern wird über Blähungszustände der Lungen berichtet. So sagt Hannemann: „Durch die reichliche Ansammlung von Schleim und Eiter in den Bronchien kommt es zu einem auffallenden Blähungszustande der Lungen, der fast immer angetroffen werden konnte. Das rührt daher, daß die Luft aus den Lungen nicht entweichen kann, weil die kleinen Bronchien durch das Sekret verlegt sind." Diese Auffassung steht im Widerspruch zu meinen obigen Ausführungen. Ich kann mir einen derartigen Mechanismus für das Zustandekommen eines Emphysems bei der Influenza nicht vorstellen, da bei totalem Verschluß der kleinen Luftwege in den nicht mehr ventilierten Lungenpartien die Luft sehr bald resorbiert wird. Wenn in den Influenzalungen geblähte Partien gefunden worden sind, so muß man diese wohl als vikariierendes Emphysem auffassen. Ich habe derartige Zustände nicht angetroffen.

Eine weitere direkte Folge der Bronchiolitis sind multiple, eitrige Bronchopneumonien, die durch einfache Fortleitung des entzündlichen Prozesses auf die Alveolen oder durch Übergreifen der Entzïndung nach eitriger Einschmelzung der Bronchiolenwand auf deren Nachbarschaft entstehen und durch die vielfach bestehenden Atelektasen eine wesentliche Förderung erfahren. Die Größe der einzelnen Herde ist auch in ein und derselben Lunge sehr verschieden. Während stellenweise nur mikroskopisch kleine Infiltrationen bestehen, kommt es an anderen Stellen durch Konfluation zu umfangreichen Herden, die in einzelnen Fällen ganze Lappen umfassen. Dazwischen gibt es alle Übergänge. Konfluierte ein- oder mehrlappige Bronchopneumonien habe ich in 17 Prozent der Sektionen gefunden. Daß es sich hierbei nicht um typische lobäre Hepatisation handelt, geht einmal aus der mehr schlafferen Konsistenz, dann aber besonders aus den nebeneinander bestehenden, verschiedenen Stadien der Entzündung hervor. Makroskopisch zeigen die Bronchopneumonien die bekannten Merkmale: mäßig feste Konsistenz, meist graurote, nur leicht gekörnte Schnittfläche mit Absonderung mäBiger Mengen dickserösen Exsudats. Reine isolierte Bronchopneumonien, d. h. bronchopneumonische Herde in normalem Lungengewebe gelegen, findet man nur stellenweise, da in der Regel die pneumonischen Knoten von splenisierten bzw. ödematösen oder sogar hämorrhagischen Gebieten umgeben sind, wodurch sie öfter der tastenden Hand verborgen bleiben. 
Doch deckt die mikroskopische Untersuchung die wahren histologischen Verhältnisse hier leicht auf. In den pneumonischen Herden sind die Alveolen fast ausschließlich ausgefiullt mit polymorphkernigen Leukozyten. Nur vereinzelt sieht man daneben abgestoßene Alveolarepithelien, Lymphozyten und Erythrozyten. Um die pneumonischen Herde herum besteht stets ein hyperämischer, häufig ein hämorrhagisoher Hof, in der weiteren Umgebung Ödem und Hyperämie. Fibrinausscheidung in die Alveolen ist im allgemeinen gar nicht oder äußerst spärlich vorhanden. Nur in dem einen Falle, in dem Pneumokokken zur Infektion geführt hatten, unterscheiden sich die auch hier bestehenden, knotigen Bronchopneumonien durch reichlichen Gehalt an Fibrin von den übrigen, rein eitrigen Formen. In einem anderen Falle boten beide Unterlappen die typischen Zeichen der Frie dländer pneumonie mit sehr reichlichem, schleimig-fadenziehendem Sekret. In Schnitten und kulturell sind hier nur die mit dicken Schleimkapseln ausgestatteten kurzen Ketten des Streptococcus mucosus nachzuweisen. Umfangreichere, hämorrhagische Bezirke habe ich nur selten gesehen. Diese Herde zeigen makroskopisch eine schwarzbraune, nach Abstreifen ziemlich trockene Schnittfläche im Gegensatz zu den mehr dunkelrotbraunen, reichlich Flüssigkeit entleerenden splenisierten Partien. Diese Hämorrhagien liegen meist zentral in den Lappen mit ganz unscharfen Begrenzungen, die keine Ähnlichkeit mit embolischen Infarkten aufkommen lassen.

Die Pneumonien sind nach dem Gesagten bronchogenen Ursprungs. Es fragt sich aber, ob auch die Ausbreitung der eitrigen Entzündung im Lungenparenchym allein auf diesem Wege èrfolgt. Man findet ziemlich häufig in den Lymphspalten des peribronchialen und perivaskulären Bindegewebes und in den Interlobularsepten dichte Streptokokkennester und Leukozyteninfiltration und Auflockerung des Bindegewebes, also eine Streptokokkenlymphangitis mit interstitiellen Entziindungsvorgängen. Bei den engen topographisehen Beziehungen des LymphgefäBsystems zum Bronchialbaum wird man nicht fehlgehen, wenn man den Ursprung dieser Lymphangitis in der Umgebung der eitrig eingeschmolzenen Bronchiolen sucht. Die frühzeitige Beteiligung des peribronchialen Bindegewebes an den eitrigen Entzündungsprozessen und die Vorliebe gerade der Streptokokkeninfektionen für das Lymphgefäßsystem lassen diesen Schluß als berechtigt erscheinen. Der Ausbreitung der Entzündungen auch auf dem Lymphwege müssen wir also eine gewisse Rolle zuerkennen, um so mehr als die fast regelmäßig gefundene Entzündung der Hilusdrüsen durch Streptokokken, die sich häufig bis zur Abszedierung steigert, kaum eine andere Erklärung zuläßt. 
Durch die Mischung dieser verschiedensten anatomischen Veränderungen in den Lungen resultiert natïrlich makroskopisch ein außerordentlich buntscheckiges Bild, das noch dadurch erhöht wird, daß in den Zentren der großen pneumonischen Herde durch die Tätigkeit der pyogenen Bakterien häufig eine umfangreiche eitrige Einschmelzung erfolgt. Derartige Lungenabszesse wurden in wechselnder Größe und Zahl von Erbsen- bis Hühnereigröße meist in Gruppen zusammenstehend in über 50 Prozent der sezierten Fälle gefunden. Sie liegen teils zentral, teils in den peripheren Lungenpartien. Im Eiter wuchern unzählige Mengen der oben beschriebenen Erreger. Die gesamten eitrigen Prozesse in den Lungen müssen außerordentlich stïrmisch verlaufen, da in einzelnen Fällen schon nach 3 bis 4 tägigem Krankenlager umfangreiche Lappenteile der Einschmelzung zum Opfer gefallen und bis zu 1200 cm Exsudat in den Pleurahöhlen gestaut sind. Außer den großen, schon makroskopisch auffallenden Abszessen findet man bei der Durchsicht der Schnitte vielfach mikroskopisch kleine, multiple Abszeßchen in engstem Anschluß an die Bronchiolen in Lungenabschnitten, die noch keine umfangreichere pneumonische Infiltration erkennen lassen. Hier ist es also nicht erst auf dem Umwege über die Pneumonie, sondern unmittelbar im Anschluß an die Bronchiolitis zur Bildung der Abszesse gekommen.

Auf die Bedeutung der an den Blutgefäßen der Lunge gemachten Beobachtungen werde ich aus äußeren Grïnden weiter unten zurückkommen. Hier sei erst auf die Leichenbefunde anderer Untersucher eingegangen.

Da ist zunächst auffallend, dab dem Ödem und der Splenisation im allgemeinen sehr wenig Bedeutung beigemessen wird, obwohl von vielen Seiten auf den außerordentlichen Saftreichtum der Lungen hingewiesen wird. Ich kann mich des Eindrucks nicht erwehren, daß unter dem Begriff der „hämorrhagischen Pneumonie", den ich nach meinem Material auf Grund meiner mikroskopischen Untersuchungen ablehnen muß, makroskopisch häufig Prozesse zusammengefaßt worden sind, die sich histologisch in Bronchiolitis, eitrige Bronchopneumonie, Hämorrhagie, Splenisation und Ödem zerlegen lassen. Vor allem sprechen Schöppler, Gruber und Schädel, Berblinger von den charakteristischen hämorrhagischen Pneumonien, während eine Reihe anderer Untersucher don Begriff umschreiben, inden sie von Pneumonien mit hämorrhagischem Charakter sprechen. Manchmal begegnet man offenbaren Widersprüchen, die sich nur dadurch erklären lassen, daß die verschiedenen pathologischen Veränderungen der Lungen nicht klar genug voneinander geschieden werden. So finde ich bei Gruber und Schädel an einer Stelle in bezug auf die Lungen die Bemerkung: „Stellen mit ganz reiner Blutung fehlten in unserem Material“, während 
einige Sätze weiter gesagt wird: „Das angrenzende Lungengewebe war durch mächtige venöse Hyperämie und breite Blutaustritte ausgezeichnet, so daß hämorrhagische Herde und eitrig durchsetzte Züge und Inseln abwechselten." Goldschmid teilt mit, daß er hämorrhagische Formen von Pneumonien nieht beobachtet hat. Das Ödem der Lungen findet besondere Würdigung u. a. bei Dietrich, Hübschmann, Borst, Marchand, Siegmund. Letzterer betont mit Recht, daß das Ödem in der Umgebung der kleinen pneumonischen Herde mikroskopisch meist schwerere Grade darbot, als es nach dem makroskopischen Befund zu erwarten war. In der Darstellung der eigentlich pneumonischen Veränderungen und der Einsehmelzungsprozesse herrscht ziemliche Übereinstimmung, wenn auch in Einzelheiten die Ansichten auseinander gehen. Die Unterschiede lassen sich größtenteils aus den lokal verschiedenen Sekundärerregern erklären und haben für die Beurteilung des Ganzen keine Bedeutung. Jedenfalls führen alle Untersucher mit Ausnahme von Oberndorfer die Pneumonien und Abszesse auf bronchogene Entstehung zurück. Oberndorfer glaubt auf Grund der weiter unten noch näher beschriebenen Veränderungen an den Lungengefäßen, die er als das Primäre ansieht, eine hämatogene Entstehung der Pneumonien und Abszesse annehmen und die Hämorrhagien als embolische Infarkte auffassen zu müssen. Nach den Mitteilungen aller anderen Untersucher und nach meinen eigenen Beobachtungen muB auch ich diese Auffassung als jrrig bezeichnen. Allein Berblinger nimmt eine vermittelnde Stellung ein, indem er die an Zahl überwiegenden bronchogenen Abszesse von den ,zweifellos auch vorhandenen hämatogenẹn Abszessen" unterscheidet. Er führt u.a. als Begründung das Vorkommen von Kokkenembolie in den Lungenkapillaren an. Hiergegen ist zu bemerken, daß die Kokkenembolie auch bei häufigem Vorkommen, wie wir noch sehen werden, nur in ganz enorm seltenen Fällen zu lokalen Entzündungsprozessen Anlaß geben, Ich selbst habe bei meinem Material derartige Fälle überhaupt nicht gefunden womit allerdings die Möglichkeit pyämischer Metastasen vor allem in Gegenden, in denen mehr Staphylokokken als Sekundärerreger gefunden worden sind, nicht bestritten werden soll. Von Borst, Siegmund, Marchand werden Fãlle von Pneumonia dissecans beschrieben. Ich habe bei meinem Material ausgeprägte Formen dieser Art nicht gesehen.

Auf einen bemerkenswerten Fall in meinem Material sei hier noch verwiesen. Es handelt sich um eine einseitige alte Spitzentuberkulose, die durch eine Influenzainfektion derart zum Aufflackern gebracht wurde, dab sie zur Ausbildung einer akuten Miliartuberkulose beider Lungen führte. Der betreffende Patient starb 22 Tage nach der Influenzainfektion. Histologisch 
bestand eine käsige Bronchiolitis. Von Residuen der Influenza bestand $u$. a. ein Ödem des rechten Oberlappens mit mäßig zahlreichen Streptokokken. Die durch die Influenza hervorgerufenen Bronchiolenveränderungen waren durch die tuberkulösen Prozesse verdeckt. Die Todesursache war in diesem Falle zweifellos die Tuberkulose, wenn auch im Blut und in den Organen spärlich Streptokokken gefunden wurden. Uber ein Aufflackern alter tuberkulöser Prozesse mit Mobilisation der Tuberkelbazillen berichten auch Dietrich, Borst, Siegmund und Marchand. Letzterer sah 5 Fälle so entstandener tuberkulöser Meningitis und 2 Fälle von akuter Miliartuberkulose. Die Mobilisierung der Tuberkelbazillen aus den alten Herden ist bei den vielfachen Entzündungsprozessen der Lungen im Verlauf der Influenza leicht erklärlich, da der dürch den Organismus gegen die tuberkulösen Herde aufgerichtete fibröse Schutzwall aufgelockert und durch eitrige Pneumonien und Abszesse durchbrochen wird. Die unkomplizierte Form der Influenza, wie ich sie weiter unten begrenze, hat meines Erachtens auf die tuberkulösen Prozesse keinen EinfluB, was auch aus den Angaben von Bochalli und Deusch über klinische Beobachtungen hervorgeht. Wenn Deusch sagt: „Der Verlauf der Grippe bei Lungentuberkulösen scheint nach den bisherigen Erfahrungen im allgemeinen kein schwerer zu sein", so ist ihm schon zuzustimmen, aber ich möchte dem hinzufügen: doch wird der Verlauf der Tuberkulose bei Auftreten von eitrigen Lungenkomplikationen durch die Influenza häufig sehr ungünstig beeinflußt. Die pathologisch-anatomischen Beobachtungen hierüber sind so eindeutig, da $B$ Zweifel daran nicht berechtigt sind. Wenn Deusch bei seinem Material in vier Fünftel der Fälle keine Verschlimmerung der Krankheit, in einem Fünftel der Fälle sogar die Tendenz zur Heilung nicht gehemmt sah, so ist das wohl dadurch zu erklären, daß die Influenza meist ohne Komplikationen verlaufen ist, wie Bochalli das für sein Material ganz besonders hervorhebt.

Die oben dargelegten eitrigen Entzündungen der Lungen greifen außerordentlich häufig auf die Pleura ïber, sei es durch Fortleitung der Eitererreger auf dem Lymphwege, sei es per kontinuitatem von subpleural gelegenen pneumonischen Herden und Abszessen. Die Pleuritiden sind meist fibrinös-eitrig mit enormen Mengen der betreffenden Erreger. Beide Pleurablätter haben sich meist dick mit gelblichen, schmierigen, fibrinösen, abziehbaren Membranen belegt, während sich im Pleuraraum stark trübe, gelblichbraune, mit fibrinös-eitrigen Flocken und Fetzen reichlich durchsetzte Flüssigkeit angesammelt hat. In anderen Fällen ist das Exsudat rein serös oder blutig-serös bei nur leicht getrübter und hyperämischer Pleura oder aber rahmig-eitrig von gelbgrüner Farbe. Zahlenmäßig liegen die Verhältnisse bei meinem Material folgendermaßen: fibrinös-eitrige und eitrige 
Formen linksseitig $8 \mathrm{mal}$, rechtsseitig $11 \mathrm{mal}$, doppelseitjg $15 \mathrm{mal}$; seröse Formen .linksseitjg 1mal, doppelseitig 5mal. Das sind im ganzen also 40 exsudative Pleuritiden bei 46 Sektionen. Die Menge des Exsudats ist sehr verschieden und beträgt meist zwischen 800 und $1600 \mathrm{ccm}$ in einem Pleuraraum, in einzelnen Fällen aber auch bis zu $2500 \mathrm{cem}$. Bei soleh reichlichen Exsudaten bostehen natürlich schwere Kompressionsatelektasen der noch nicht entzündeten Lungenpartien. In dẹ Material von Oberndorfer bildeten doppelseitige Pleuritiden die Ausnahme. Ich habe sie in über der Hälfte der Fälle gesehen. Darin kann ich Oberdorfer zustimmen, daß bei den doppelseitigen Pleuritiden meist die eine Seite schwerer und länger erkrankt schien. Ich nahm zunächst an, daß die blutig-serösen Exsudate postmortal infolge hochgradiger Hyperämie und Ödems der Lungen transsudiert seien. Eine Nachprüfung der betreffenden Fälle ergab aber, daß diese Exsudate verschiedentlich schon längere Zeit vor dem Tode klinisch dureh Punktion oder Rippenreseltion nachgewiesen wurden, so daß es sich also auch hier um entzündlich entstandene seröse Ergiusse handelt. Synechien und Adhäsionen sind außerordentlich häufig ( $35 \mathrm{mal}$ ) und bestehen auch in den 6 Fällen, in denen keine Exsudation stattgefunden hatte, so daß man sagen kann, daß die Plewa in allen Fällen an den entzündlichen Vorgängen der Lungen sich beteiligt hat. Borst berichtet bei 133 Sektionen in 78 Fällen über Pleuraadhä̈sionen ,als Residuen früherer Frkrankungen“. Ich möchte bei diesem hohen Prozentsatz annehmen, daß zum mindesten ein Teil dieser Adhäsionen erst im Verlauf der Influenza neu entstanden ist. Durch das bunte Gemisch der entzündlichen Erscheinungen an Lungen und Pleura muß die klinische Diagnostik außerordentlich unklar werden. Nur so kann ich es verstehen, daß bei meinem Sektionsmaterial in 24 Fällen, also in 60 Prozent ein- oder doppelseitige Pleuritiden klinisch nicht erkannt worden sind, obwohl in einem Drittel dieser Fälle Exsudate von 800 bis $1500 \mathrm{ccm}$ vorhanden waren. Der Ablauf der exsudativen Entzündungsprozesse an der Pleura läßt sich klar erkennen, wenn die Untersuchungen des Krankenmaterials, insbesondere von den mehrmals untersuchten Fällen, mit verwertet werden. Im Anfang der Entzündung ist das Exsudat rein serös und enthält keine oder nur so spärlicho Bakterien, daß ihr Nachweis nur durch Bouillonanreicherung gelingt. $\mathrm{Zu}$ dieser Zei, ergibt die zytologische Untersuchung eine fast reine Lymphozytose. Ziemlich schnell tritt unter zunehmendem Bakteriengehalt eine Umstellung im zytologischen Bild ein, indem die anfangs nu ganz vereinzelt vorhandenen polymorphkernigon Leukozyten beträchtlich an Zahl gewinnen und schlieBlich nach Verschwinden der. Lymphozyten gänzlich das Bild beherrschen. Gleichzeitig wird das Exsudat trübe und mit fibrinös-eitrigen Flocken durchsetzt. Es besteht 
also auch bei den bakteriellen eitrigen Pleuritiden nicht tuberkulöser Ätiologie ein seröses Initialstadium mit ganz ausgeprägter Lymphozytose, was bei der Verwertung des zytologischen Befundes für die Tubcrkulosediagnostik nicht ohne Bedeutung sein dürfte.

Die Entzündungen der Pleura greifen ziemlich oft auf die benachbasten serösen Höhlen über. Bei meinem Material sah ịch in 9 Fällen cine fibrinöseitrige Perikarditis, in 4 Fallen eine diffuse, fibrinos-eitrige Penitonitis durch Streptokokken. Der Charakter dieser Entzündungen entspricht vollkommen dem der fibrinös-eitrigen Pleuritiden, so daß eine nähere Beschreibung sich erübrigt. Bei der engen Nachbarschaft von Pleura und Perihard ist cin Durchwuchein der Streptokokken nichts Utberraschendes, da ja beide in größaren Flächen fast unmittelbar aneinanderliegen. Das Übergreifen der Entzündung von der Pleurahöhle auf die Bauchhöhle erscheint weniger leicht zu erklären, da zwischen Pleura und Peritoneum außer Bindegewebe entweder dickere Muskelschichten oder widerstandsfähige Sehnenplatten eingelagert sind. Doch überwinden gerade die Streptokokken wegen ihrer Affinität zum Lymphgefäßsystem diese Widerständo ziemlich leicht, da zwischen Pleura und Peritoneum durch das Diaphragma hindurch zahllose Lymphverbindungen bestehen. In histologischen Präparaten von Querschnitten des Zwergfells habe ich die Lymphbahnen im Perimysium dicht mit Streptokokken ausgefüllt gefunden, so daß sich ganze Bákterienbrücken von der Pleura zum Peritoneum hinziehen. Für ein direktes Übergreifen der Infektion von der Brusthöhle auf die Bauchhöhle spricht auch der Umstand, daß die Peritonitiden die schwersten Erscheinungen entweder an der Konvexität des rechten Leberlappens oder in der Milzgegend hervorgerufen hatien, je nachdem sie von der rechten oder linken Pleura fortgeleitet waren. Wenn Schmieden betont, daß Peritonitis auch als selbständige Grippemetastase 7. B. infolge Durchbruchs einer vereiterten Mesenterialdrüse entstehen kann und König Peritonitis ohne Pleuraempyem beobachtet hat, so muß man die Möglichkeit dieses hämatogenen Infektionsmodus wohl anerkennen, aber in der Praxis wird er kaum in Betracht kommen. Die Beobachtungen von Schmieden und König an ihrem klinischen Material möchte ich mit Vorsicht beurteilen, da ich ja oben bereits darauf hingewiesen habe, daß bei meinem Sektionsmaterial die Pleuritis in 60 Prozent der Fälle klinisch übersehen worden ist.

In 4 Fällen hatte die eitrige Entzündung der Pleuren auf das Mediastinum anterius übergegriffen. Das Bindegewebe war eitrig durchsetzt und in einem Falle sogar in großer Ausdehnung zu mehreren hühnereigroßen Abszessen eingeschmolzen. Es war dies ein besonders schwerer Fall, in dem 
allein im rechten Pleuraraum $2500 \mathrm{cem}$ rahmiger, gelblicher Eiter vorgefunden wurde.

Als letzte unmittelbare Folge der eitrigen Bronchiolitis hatte ich die Bakteriämie bzw. Sepsis bezeichnet. In der Lunge bestehen bekanntlich zwischen Bronchien und Blutgefäßen enge topographisehe Beziehungen, da die Blutgefäße den Bronchien folgen und ihnen entsprechend sich verteilen. Bei der oben beschriebenen eitrigen Einschmelzung der Bronchien sind deshalb die Gefäße außerordentlich bedroht und es besteht die Gefahr daß die eitrige Entzündung auf die Gefäße übergreift. Daß dies tatsächlich häufig geschieht, geht aus den histologischen Präparaten einwandfrei horvor. Hier zeigen die Wandungen besonders der kleinen Arterien häufig Leuk0zyteninfiltration, Verdickung der Intima z. T. mit Thrombenbjldung und stellenweise sogar partielle eitrige Einschmelzung mit Einbruch des eitrigen Materials in das Gefäßlumen bei teilweise offenem Blutstrom. Wenn man bedenkt; wie unendlich kleine Partien des erkrankten Gewebes der histologischen Untersuchung zugänglich gemacht werden, so wird man derartigen Befunden um so höhere Bedeutung zuerkennen müssen. Fördernd wirkt bei der Ausbreitung der eitrigen Entzündung in der Umgebung der Gefäße auch die Lymphangitis im perivaskulären Bindegewebe. Schwere Veränderungen an den kleinen Gefäßen werden in der Lunge nur in eitrig entzündeten Bezirken gefunden, während sie in rein ödematösen oder normalen Abschnitten fehlen. Hier sieht man höchstens geringe Rundzelleninfiltration mit spärlichen Leukozyten um die Gefäße herum und auch das nur sehr selten. Nicht die Gefäßschädigung ist also, wie Oberndorfer meint, das Primäre, sondern die eitrige Entzündung greift sekundär von den Bronchiolen oder pneumonischen Herden auf die Gefäße uiber. $\mathrm{Da}$ für den Übertritt der Kokken in die Blutbahn tatsächlich in erster Linie die Bronchiolitis verantwortlich zu machen ist, wird durch diejenigen Frïhtodesfälle erwiesen, in denen außer starkem Ödem und der üblichen Bronchiolitis mit kleinsten pneumonischen Infiltrationen regelmäßig pine zum Teil beträchtliche Bakteliämie festgestellt wurde.

Ob man die Allgemeininfektion als Bakteriämie im Sinne von Kocher und Tavel, als Sepsis oder Pyämie bezeichnen soll, müßte eigentlich in jedem einzelnen Falle nach den klinischen und anatomischen Befunden entschieden werden. Metastatische Prozesse, die im Sinne einer Pyämie zu deuten wären, habe jch bei meinem Material nicht gefunden. Daß aber pyämische Metastasen im Verlauf der Influenza auftreten, darüber liegen zahlreiche Mitteilungen in der Ljteratur vor. So wird z. B. berichtet uiber multiple Nierenabszesse von Knack, Borst und Hannemann; über metastatische Abszesse und Gelenkeiterungen von Marchand, Schmieden; über Otitis 
media von Gruber und Schädel, Koepchen, Hirsch; über eitrige Meningitis von Dietrich, Goldschmid, Borst, Berblinger, Busse, Hannemann; über Endokarditis von Dietrich, Goldschmid, Borst, Siegmund, Marchand, Schott; über Venenthrombosen von Goldschmid, Orth, Jacob, Busse, Hannemann. Diese Mitteilungen sprechen für sich allein schon dafür, daß wir das Vorkommen der Bakterien im strömenden Blut zum mindesten als Sepsis zu deuten haben. Ich habe bei den histologischen Untersuchungen der inneren Organe etwa in der Hälfte der Fälle sog. Kokkenembolie in größerer oder geringerer Zahl in den kleinsten Arterien und Kapillaren gefunden. Hierunter befinden sich Fälle, die 1 und 2 Stunden nach dem Tode zur Sektion kamen, bei denen also eine postmortale Vermehrung der Kokken noch nicht in Frage kam. Im Verein mit den positiven Kokkenbefunden im Krankenblut und dem stetigen Nachweis von Eiter-. erregern im Leichenblut muß man an dem Bestehen einer Sepsis im Verlauf der komplizierten Influenza festhalten. Bei meinem Material haben die Kokkenembolie nie zu infarktähnlichen Zirkulationsstörungen geführt und keinerlei erkennbaren Reiz auf ibre Umgebung ausgeübt. In fast allen histologisch untersuchten Organen habe ich auffallend viel Blutpigment. gefunden, wohl ein Ausdruck der Einwirkung des Hämolysins der pyogenen Kokken auf die Erythrozyten. Auf der gleichen Wirkung beruht auch die häufig beobachtete, eigenartig lackfarbene Beschaffenheit des Blutes, auf die auch Dietrich aufmerksam macht, und auch der Jkterus. Zeichen einer allgemeinen Gefäßschädigung habe ich nicht festzustellen vermocht. Außer den beschriebenen lokalen Veränderungen der Lungengefäße habe ich nur an den kleinen Arterien der Milz des öfteren hyaline Quellung der Intima ohne zellige Infiltration der Wandung gesehen.

Die bisher nicht erwähnten, im folgenden noch zu schildernden Organveränderungen lassen sich meines Erachtens zwanglos als Folge der Sepsis erklären. Die Milz reagiert in über der Hälfte der Fälle mit typischen Veränderungen. In allen Fällen mit schnellem Krankheitsverlauf, die etwa bis zum 6. Krankheitstage ad exitum kamen, besteht als Einleitung des septischen Milztumors ganz beträchtliche kongestive Hyperämie mit erheblicher Zunahme des Volumens bei tiefdunkelroter Schnittfläche und noch ziemlich gut erkennbaren Follikeln. Die eigentlich septischen Milztumoren von Gewichten bis über $300 \mathrm{~g}$ mit grauroter, verwaschener Schnittfläche und weicher Pulpa betreffen sämtlich Fälle, die erst im späteren Verlauf der Krankheit zugrunde gegangen sind. Auffallend große Milzfollikel babe ich nicht gesehen, wie ich Obernd orfer gegenüber bemerken möchte. Gewöhnlich waren die Follikel im Gegente!l sehr klein, was u. a.' auch Goldschmid und Marchand anführen. 
Die Nieren zejgten in über der Hälfte der Fälle starke, alktive Hyperämie bei zum Teil erheblicher Vergrößerung des Organs mit praller Kapselspannung. In 6 Fällen sah ich makroskopisch und mikroskopisch herdförmige Glomerulonephritiden bzw. Nephrosen, wovon aber 1 Fall bereits vor Ausbruch der Influenza wegen Nephritis in Behandlung war. In den unteren Abschnitten der Harnkanälchen steckten in über 50 Prozent deı Fälle in wechselnder Zahl hyaline Zylinder. Bei den Glomerulonephritiden waren die Kapselräume herdförmig bei stark hyperämischen, nicht zellig infiltrierten Schlingen mit ausgefälltem Eiweiß angefüllt, während bei den Nephrosen eine herdförmige fettige Degeneration der Epithelien der gewundenen Harnkanälchen erfolgt war. Die Nierenschädigungen können nur durch die im Blute kreisenden Toxine der Sekundärerreger ausgelöst sein, da nach den Angaben der Kliniker die Nieren in den unkomplizierten Fällen nicht in Mitleidenschaft gezogen werden. Eine direkte Bakterieneinwirkung kommt auch nicht in Frage, da die Herde keinerlei Abhängigkeit von den Kokkenembolie, die übrigens ganz überwiegend in den Arteriolae rectae stecken, crkennen lassen. Die Angaben über die Nierenbefunde bei Influenza von seiten anderer Beobachter weichen sehr voneinander ab. Während die Mehrzahl der Pathologen und Kliniker keine oder nur sehr geringe abnorme Befunde erheben konnte, berichtet Dietrich über Erhöhung der Gewichte, Trübung und Verbreiterung der Rinde in einem Drittel seiner Fälle, Marchand über recht häufige parenchymatöse Trübung, ziemlich verbreitete fettige Entartung der gewundenen Kanälchen, in einzelnen Fällen auch über Anfänge entzündlicher Veränderungen. Durch Beobachtungen an klinischem Material kamen Adler und Kaznels on zu dem Scbluß, daß Abbuminurie und Zylindrurie bei den pneumonischen Formen zur Regel zu gehören scheinen. Auch Hoppe-Seyler, Hoffmann und Keuper und Knack sprechen sich in ähnlichem Sinne aus.

Die Leber ließ in 85 Prozent Zeichen der trüben Schwellung mit Vergrößerung des Organs in 6 Fällon auf ca. $2000 \mathrm{~g}$ und mehr erkennen. Stauungserscheínungen mit geringer Atrophie der Leberzellbalken um die Zentralvenen wurde nur in 15 Prozent beobachtet. In der Hälfte der Fälle wurde histologisch eine zum Teil beträchtliche Rundzelleninfiltration in dem die portalen Gefäße begleitenden Bindegewebe gefunden, das vielfach deutliche Wucherungserscheinungen unter Beteiligung der Gallenkapillaren zoigte. In einem dieser Fälle war die Bindegewebsneubildung bereits so vorgeschritten, $d a \beta$ sie schon makroskopisch deutlich in Erscheinung trat. Es handelt sich hier um interstitielle Entzündungsvorgänge in Anlehnung an die Gefäße, die wohl auch durch den Reiz der im Blut kreisenden Bakterien- 
toxine ihre Erklärung finden müssen. Interstitielle Wucherungserscheinungen sahen in vereinzelten Fällen auch Schöppler und Busse. Die abführenden Gallenwege waren auch in den Fällen mit Ikterus stets durchgängig. Gallenthromben habe ich nicht beobachtet.

An den übrigen Organen wurden keine wesentlichen pathologischanatomischen Befunde erhoben, die als direkte oder indirekte Folgen der Influenza gedeutet werden könnten. Das Herz war nur in 3 Fällen mäßig, in 1 Falle stärker hypertrophisch, nicht dilatiert. In einem dieser Fälle bestand eine alte Obliteration des Herzbeutels. Der Klappenapparat war stets funktionstüchtig und zeigte keine frischen Entzündungen. Das Myokard war mit Ausnahme von 2 Fällen von fester Konsistenz und normaler Farbe. Mehrfach als Stichproben ausgeführte histologische Untersuchungen ließen geringe Pigmentierung um die Kerne herum, aber keinerlei fettige Degeneration erkennen. Von anderen Untersuchern wurden des öftern Fälle rekurrierender, selten frischer Endokarditis gefunden. Auffallende Myokardveränderungen beschreibt Sehöppler: ,Von seiten der anderen Organe kam hauptsächlich am Herzen der Zustand der fettigen Degeneration zur Beobachtung. Das Herz erwies sich als schlaffer, in seinen Höhlen erweiterter, gelbbrauner Sack. Das Herzfleisch war stark brüchig." Diese Befunde werden von anderer Seite, wenigstens in diesem Umfange, nicht bestätigt. Schott beobachtete an klinischem Material keinen Fall von Myokarditis, von dem sich hätte feststellen lassen, daß lediglich durch die Influenza der Degenerationsproze $B$ hervorgerufen worden war.

Einen gegen dịe Norm vergrößerten Thymus sah ich nux einmal. In den Nebennieren bestand des öfteren Hyperämie der Zona reticularis und fascicularis. Der Lipoidgehalt war vielfach herabgesetzt. Im Verdauungstraktus waren auch in den Fällen, in denen klinisch starke Diarrhoen und Erbrechen bestanden hatten, keinerlei abnorme Veränderungen festzustellen. Über positive Befunde berichten u. a. Simmonds, Borst und Busse. Simmonds sah einmal auf der Magenschleimhaut Schorfbildungen, Borst 7 mal akute Gastroenteritis und 2mal Erosionen der Magenschleimhaut, Busse im Magen häufig hämorrhagische Erosionen und gelegentlich flächenhaft ausgebreitete oberflächliche Substanzverluste mit hämorrhagischen Grunde, einmal im Duodenum noch Erosionen, fünfmal im oberen Dickdarm streiferweise angeordnete Schorfbildungen. Beckmann berichtet über Darmblutungen bei leicht verlaufener Influenza, als deren Ursache rektoskopisch kleine bis erbsengroße blutende Stellen der Rektalschleimhaut ohne eigentliche Geschwürsbildung nachgewiesen werden konnten. 
Nachdem ich so im vorstehenden die außerordentlich vielseitigen pathologisch-anatomischen Befunde bei der Influenza in morphologischer und genetischer Beziehung dargelegt habe, kann ich die Frage aufwerfen: Wie weit gehören die anatomjschen Veränderungen zum Bilde der „reinen“" Influenza und wo haben wir die Grenze gegenüber den Komplikationen zu ziehen? Obwohl diese Frage für die gesamte Beurteilung der Influenza von grundlegender Wichtigkeit ist, finde ich in der mir zur Verfügung stehenden Literatur hierüber äußerst selten und nur oberflächliche Argaben. Dietrich, Hübschmann, Berblinger und anscheinend auch Borst rechnen zu den primären Erscheinungen der Influenza die Laryngotracheabronchitis, die Bronchiolitis, das Lungenödem und auch noch die azinösen pneumonischen Herde. Oberndorfer sieht in seiner oben schon näher skizzierten Auffassung vor allem die Blutungen in den Lungen als das Primäre an. Stimmen die Mitteilungen und Auffassungen der Kliniker mit den hier geäußerten Ansichten überein? Es liegt von klinischer Seite eine derart große Zahl von ausführlichen Angaben vor, daß ein Eingehen auf diese Literatur im einzelnen zu weit führen würde. Es ist dies auch überflüssig, da die klinischen Symptome, die für die unkomplizierte Form der Influenz a von den verschiedenen Untersuchern angeführt werden, fast in allen Einzelheiten übereinstimmen. Hiernach verlaufen diese leichten Fälle in der Regel mit Fieber, Kopfschmerzen, besonders Stirnkopfschmerz, Rückenund Gliederschmerzen, Abgeschlagenheit, Kratzen im Hals, Stechen und Brennen unter dem Brustbein, Injektion der Konjunktiven, Rötung der Rachenschleimhaut, Rötung und Schwellung der Trachealschleimhaut besonders im unteren Drittel, mit quälendem, trockenem Husten ohne oder höchstens mit spärlichem, schleimigem, bakterienarmem Sputum, seltener Rötung der Nasenschleimhaut ohne profuse Sekretion aber mit Blutungen, Roseolen. Von zahlreichen Seiten wird besonders darauf hingewiesen, daß bei den leichten Fällen im allgemeinen die Lungen überhaupt nicht beteiligt oder nur selten vereinzelte bronchitische Geräusche zu hören sind. Schon das Auftreten der diffusen Bronchiolitis mit eitrig werdendem Sputum wird fast durchweg als den Verlauf komplizierend angesehen. Der Kliniker hat also eine andere Auffassung über den Symptomenkomplex der ,unkomplizierten" Influenza als die oben angeführten Pathologen. Seinem Urteil ist aber von vornherein mehr Gewicht beizulegen, da er alle Stadien der Krankheit, vor allem auch die leichten Fälle zu Gesicht bekommt, während der Pathologe nur von den tödlich endenden Rückschlüsse ziehen kann. .Macht man sich, um nicht von falschen Voraussetzungen auszugehen, von jedem Vorurteil über die Bedeutung der Pfeifferschen Bazillen frei, so muß man aber nach meinen Erfahrungen auch vom pathologisch-anatomischen $\mathrm{Ge}$ - 
sichtspunkten aus die eitrige Bronchiolitis als erste und in ihren Folgen schwerste Komplikation der Influenza betrachten. Ich habe weiter oben hervorgehoben, daß der einzige, regelmäßig wiederkehrende und von allen Seiten bestätigte Befund, der auch in den leichten, unkomplizierten Fällen klinisch durch Spiegeluntersuchung und Bronchoskopie einwandfrei gesehen wurde, die katarrhalische Tracheobronchitis ist. Daß diese der Wirkung dęs spezifischen Influenzaerregers zuzuschreiben ist, darüber herrscht, wenn man von Oberndorfer absieht, volle Einigkeit. Wollte man nun die eitrige Bronchiolitis ebenfalls als ein Produkt des spezifischen Virus betrachten, so müßte der gleiche Krankheitsstoff auf einer histologisch nahezu gleichartig gebauten Schleimhaut bei demselben Organ in dem einen Abschnitt eine rein katarrhalische, in dem anderen Abschnitt eine rein eitrige Entzündung hervorrufen, ein Vorgang, der meines Erachtens absolut unerklärlich sein würde. Wie ich oben mit aller Schärfe betont habe, ist die Entzündung der Trachea und ihrer großen Äste einerseits und die Entzündung der Bronchiolen andererseits in ihrem Wesen und ihren histologischen Einzelheiten derartig grundverschieden, daß hier zweifellos verschiedene Ursachen zugrunde liegen müssen, und tatsächlich habe ich ja auch in dem Bronchioleninhalt stets Eitererreger gefunden, während die Genese der katarrhalischen Tracheobronchitis nicht geklärt werden konnte. Wir haben also auch vom pathologisch-anatomischen Standpunkt aus die eitrige Bronchiolitis mit allen ihren mittel- und unmittelbaren Folgeerscheinungen als Komplikation infolge Sekundär- oder Mischinfektion anzusprechen. Als zum Bilde der reinen Influenza gehörig erachte ich lediglich die katarrhalischen Schleimhautaffektionen im Respirationstraktus und an den Konjunktiven als Lokalwirkungen der spezifischen Erreger und die Neigung zu Blutungen (Nasen-, Darmblutungen, Petechien und Roseolen, Hirnpurpura) als Toxinwirkung.

Von klinischer Seite wird vielfach eine Einteilung der Influenza in verschiedene Formen vorgenommen, die lediglich den Symptomen, nicht aber den kausalen Zusammenhängen Rechnung trägt. So unterscheidet beispielsweise $\nabla$. Strümpell folgende 6 Formen: die rein toxische, die schwere nervöse, zerebrale, die katarrhalische, die rheumatoide, die gastrointestinale, die pneumonische. Ich halte eine derartige Gıuppierung für erzwungen, da. nicht nur zwischen einzelnen Formen fließende Übergänge bestehen, sondern auch fast stets bei dem einzelnen Kranken die Symptomenkomplexe derart weit ineinander übergreifen, daß in zahlreichen Krankheitsfällen Zweifel in ihrer Zugehörigkeit zu bestimmten Gruppen sich ergeben müssen. Auch für die Klinik halte ich die Einteilung in die reine und komplizierte Form, wie ich sie vorhin abgegrenzt habe, für glücklicher, da hierbei die ursäch- 
lichen Momente und gleichzeitig auch die Prognose Berücksichtigung finden. Sie muß von dem Moment an wesentlich ungünstiger beurteilt werden, wo die Zeichen der Bronchiolitis und damit die Gefahr der von ihr ausgehenden anderen Komplikationen auftreten.

Eine andere interessierende Frage, die in der Literatur kaum crörtert worden ist, ist die der Todesursachen. In bezug auf die unkomplizierte Form der Influenza stimmen die Ansichten dahin überein, daß sie allein nie zum Tode führt, es sei denn mittelbar bei schon bestehenden, anderen lebensgefährlichen Zuständen. Auch ich muß mich zu dieser Auffassung bekennen, da bei meinem Sektionsmaterial in allen Fällen Komplikationen von seiten der Lungen bestanden. Welche der zahlreichen Komplikationen bedingt aber nun in der Regel den letalen Ausgang? Es ist bequem zu antworten: der Tod war immer ein Herztod, wie das von anderer Seite geschehen ist. Jeder Tod ist letzten Endes ein Herztod. Als Todesursache kann man aber doch nur die krankhaften Prozesse ansprechen, die das Versagen der Herztätigkeit veranlaßt haben. Ein Herztod in diesem ursächlichen Sinne kann nach meinen und den Befunden anderer nicht in Betracht kommen, da degenerative Herzmuskelveränderungen, Klappenerkrankungen oder sonstige im Herzen selbst begründete, krankhafte Zustände zu den seltenen Ausnahmen gehören. Andere Autoren wollen die Gründe für die Insuffizienz des Herzens in einem „Versagen der Vasomotoren“, ,,in einer toxischen Lähmung der Gefäßmuskulatur" erblicken. Wieder andere sehen die komplizierte Form der Influenza mit Recht als Toxikose an, überschätzen aber offenbar die Toxinwirkung in Hinsicht auf den tödlichen Ausgang, während sie die lokalen Veränderungen in den Lungen nicht genügend berücksichtigen. Nach meinen eigenen Erfahrungen läßt sich die Frage der Todesursachen uiberhaupt nicht einheitlich beantworten, sondern muß in jedem Falle für sich analysiert werden. Dabei ergibt sich für die Frühtodesfälle, die in den ersten Krankheitstagen oft ziemlich schnell letal verlaufen, ein ziemlich übereinstimmendes Bild: schwere eitrige Bronchiolitis ohne oder mit geringen pneumonischen Infiltraten, aber hochgradigem Lungenödem. Wir haben hier zweifellos als Todesursache eine Erstickung infolge Verlegung der feinen Luftwege und infolge akuten, entzündlichen Ödems der Lungen anzunehmen. Der Herzmuskel muß hier besonders schnell seinen Dienst versagen, da ihm plötzlich viel zu wenig Sauerstoff zugeführt wird, während ihm andererseits durch die Erschwerung des kleinen Kreislaufs enorme Mehrarbeit aufgebürdet wird. Die starke Zyanose, die beschleunigte, angestrengte und rasselnde Atmung, die zahlreichen feuchten klein- und mittelblasigen Rasselgeräusche, das Knisterrasseln, das, wenn überhaupt noch ausgehustet wird, 
schaumige, blutig-seröse Sputum läßt im Verein mit dem akuten Verlauf diese Fälle auch klinisch unschwer als Lungenödem diagnostizieren. Die pneumonischen Herde sind bei diesen Fällen in der Regel noch so klein, daß ihnen erhebliche Bedeutung nicht zukommt. Bei den im vorgeschrittenen Stadien der Influenza Verstorbenen sind die entzündlichen Prozesse der Lungen und Pleura meist so hochgradig ausgebildet, daß man wirklich nicht nach anderen Todesursachen zu suchen braucht. Immerhin wird die Sepsis mit ihren toxischen Folgen erschwerend und beschleunigend den Gesamtverlauf beeinflussen, aber die Hauptursache bleibt wohl stets die hochgradige Einschränkung des noch funktionstüchtigen Lungengewebes. Ich habe bei meinem Material keinen Fall gesehen, bei dem ich zur Erklärung der Herzinsuffizierung zu den Vasomotoren meine Zuflucht hätte nehmen müssen. In dem einzigen Falle, in dem der Lungenbefund $Z$ weifel an der Todesursachegelassen hätte, war ein hochgradiges Ödem des Kehlkopfeinganges und der Glottis vorhanden, das nach dem klinischen Verlauf und dem Sektionsbefund mit Sicherheit als Todesursache angesehen werden konnte. Von den entzündlichen Prozessen in den Lungen nehmen nach meinem Material in den vorgeschrittenen Fällen die pneumonischen Infiltrationen wohl den größeren Anteil für sich in Anspruch, doch kommt auch dem Ödem neben den Pneumonien eine ganz besondere Bedeutung zu. Das geht auch aus klinischen Erfahrungen hervor. Es kommt nicht selten bei schon bestehenden Pneumonien zur akuten Verschlimmerung des Krankheitsbildes unter schnell zunehmender Zyanose, Pulsversehlechterung und reichliichem, blutig-seröscm Sputum. Diese bedrohlichen Zustände sind nur durch das zur Pneumonie hinzutretende akute, entzündliche Ödem bis dahin funktionstüchtiger Lungenabschnitte zu erklären, wofür ja auch die pathologisch-anatomischen Befunde eindeutig sprechen. Atelektasen und Hämorrhagien können natürlich ergänzend zu den Pneumonien und Ödemen hinzutreten. $\mathrm{DaB}$ in vereinzelten Fällen auch metastatische Prozesse, wie eitrige Meningitis, Endokarditis, multiple Nierenabszesse u. a., unabhängig von den Lungenkomplikationen zum Tode führen können, soll natürlich durch obige Ausführungen nicht ausgeschlossen werden. Meine Auffassung der Todesursachen erklärt auch die Machtlosigkeit der therapeutischen MaBnahmen, insbesondere der Herzmittel.

An die Frage, weshalb vielfach gerade kräftige, bis dahin gesunde und widerstandsfähige Individuen in den besten Jahren der Mischinfektion bei der Influenza zum Opfer fallen, sind von mehreren Seiten theoretisch interessante Frörterungen geknüpft worden. Der Gedankengang Fis schers ist kurz folgender: Die Mischinfektion wird bei der Influenza durch Endotoxinbakterien bedingt. Die vitalen Abwehrreaktionen sind bei den kräftigen Personen von besonderer Heftigkeit, so daß es bei plötzhcher Abtötung und 
Auflösung der Bakterien zu schlagartiger Überschwemmung des betreffenden Körpers mit den Innengiften kommt, denen der Organismus in wenigen Stunden erliegt. Fischer stellt nun einen Versuch Muchs in Parallele mit diesem Gedankengang: Zwei Versuchstiere erhalten beide eine hohe, aber nicht tödliche Dosis von Endotoxinbakterien, das eine der Tiere zugleich einen Immunkörper. Dieses Tier stirbt, weil es den plötzlich freiwerdenden Innengiften der durch den Immunkörper abgetöteten Bakterien erliegt. Das zweite Tier erkrankt, bleibt aber am Leben. Dieser Tierversuch ahmt seiner Ansicht nach völlig die Verhältnisse bei der Influenzamischinfektion nach. Dieser ganze Gedankengang ist meines Erachtens irrig und auch der Vergleich ist deplaziert. Die Folgerungen wären richtig, wenn man annehmen würde, daß der kräftige Organismus ledgglich Bakteriolysine, nicht aber auch Antitoxine zu bilden imstande wäre, eine Annahme, für die keine Grundlagen vorhanden sind. Bei dem Versuch Muchs geht das eine Tier nur zugrunde, wenn der gleichzeitig verabfolgte Immunkörper nur bakteriolytisch und nicht antitoxisch wirkt. Bei der Influenza liegen aber die biologischen Verhältnisse durchaus anders, da der betreffende Organısmus ja nur das Antigen, aber keine spezifischen Antikörper aufnimmt. Diese muß er ja erst selbst bilden, und zwar steht ihm zur Bildung der Bakteriolysine wie der Antitoxine die gleiche Zeit zur Verfügung. Wenn auch die Antitoxinbildung in manchen Fällen nicht gleichen Schritt mit der Bildung der Bakteriolysine hält, so läßt sich meiner Ansicht nach ein Tod innerhalb weniger Stunden hieraus nicht erklären. Zum mindesten muß man der allgemeinen Gültigkeit einer derartigen Erklärung unbedingt widersprechen. Fis cher geht übrigens auch von einer falschen Voraussetzung aus, wenn er annimmt, daß ,in auffälligster Weise nur die Kräftigsten der Krankheit erlagen". Bei meinem Material waren, wie schon oben erwähnt wurde, 24.Prozent der Leichen grazil gebaut, in mehr oder weniger stark reduziertẹm Ernährungszustand, $16 \frac{1}{2}$ Prozent waren von mittelkräftigem Körperbau, obwohl mein Material nur aus Heeresangehörigen bestand. Gegen die Ausführungen Fischers nimmt auch Grabisch Stellung. Er kommt zum gegenteiligen Schluß: Die kräftigen Individuen erliegen der Mischinfektion aus Mangel an Schutzstoffen. Bei kachektischen und unterernährten Personen dringen ständig Krankheitserreger in den Körper ein und veranlassen ihn dauernd zur Bildung von Schutzstoffen, während bei den gesunden Individuen bei intaktem Organismus keine Antigene eindringen, also auch keine Antikörper zur Entwicklung kommen können. Bei der Influenzamischinfektion sollen also bei den ersteren Personen die Bakterien auf bereits zahlreich vorhandene Schutzstoffe treffen, bei den kräftigen Individuen dagegen frei ihre Wirkungen entfalten können. Schon im Hinblick auf die oben wiedergegebene Zusammen- 
setzung meines Materials kann diese Auffassung nicht befriedigen. Ich erkläre mir das Überwiegen der jungen, kräftigen Personen in widerstandsfähigem Alter sehr viel einfacher. Wie aus meinen epidemiologischen Mitteilungen noch hervorgehen wird, bevorzugt die Influenza ganz allgemein insbesondere das jugendliche Alter um 20 herum. Wenn also diese Altersstufe mit ihren meist gesunden und kräftigen Vertretern weitaus den größten Prozentsatz an Kranken liefert, so ist doch gar nicht zu verwundern, daß auch ein großer Teil der Todesfälle hierauf entfällt, obwohl das relative Verhältnis zwischen Morbidität und Mortalität, wie wir noch sehen werden, zu ungunsten der höheren Altersklassen sich verschiebt, in Wirklichkeit also auf eine höhere Widerstandskraft der jugendlichen Personen schließen läßt. Daß die plötzlichen Frühtodesfälle fast ausschließlich Personen mit ganz besondẹs kräftiger Konstitution betrafen, läßt sich vielleicht so erklären, daß das entzündliche Ödem der Lungen, das wir ja auch als Abwehrreaktion des Organisnus zu betrachten haben, bei diesen Personen schneller und umfangreichor auftritt als bei stark geschwächten Tndividuen.

\section{Bpidemiologie.}

Meine epjdemiologischen Erfahrungen fußen auf den Beobachtungen, die beim Verlauf der Influenza in den fast 8000 Mann starken Truppenteilen der Garnison Schwerin gemacht wurden und auf dem statistischen Material der 11300 Mitglieder zählenden Ortskrankenkasse sowie des Standesantísberirks Schwerin. Soweit ich die Ermittlungen nicht persönlich machen konnte, habe ich sie durch sich gegenseitig kontrollierende Meldungen nachprüfen und bei Widersprïchen etwaige.Fehler klarstellen können, so daß ich glanbe, einwandfroje Mitteilungen und Zahlen zu liefern. Bei den Truppenteilen wurde bei allen Erhebungan von den einzelnen Kompagnien ausgegangen, um über den Verlauf der Influenza gerade in den kleineren Truppenverbänden, die im wesentlichen Wohngemeinschaften entsprachen und auch sonst in engem Kontakt miteinander standen, Aufklärung zu gewinnen.

Betrachtet man zunächst den zeitlichen Allauf der hicsigen Epidemie im ganzen, so hat man ein getreues Bild der großen Pandemie, wie sie in zwei scharf voneinander getrennten Wellen übor die Länder hinweggezogen ist. Bej den Truppenteilen wurden ungefähr um die Mitte des Monats Mai 2 vereinzelte Fälle von Influenza gemeldet. Während des Monats Juni war eine allmähliche Zunahme der Erkrankungen unverkennbar, doch blieb die Gesamtzahl im ganzen Monat mit 32 noch verhältnismäßig sehr gering. Ein urplötzliches Ansteigen der Erkrankungsziffern fand in den ersten Tagen 
des Juli statt, wo allein in den ersten 5 Tagen 173 Mann von der Influenza befallen wurden, womit del Höhepunkt der e1sten Welle in steilstem Kurvenanstieg erreicht war. In der Zeit vom 6. bis 10. Juli hielt sich zwar die Kurve mit 131 Erkrankungen noch ziemlich hoch, doch war schon hier wieder ein deutliches Abflauen bemerkbar. In den nächsten 5 Tagen folgte ein steiler Abfall auf 31. Ungefähr auf dieser Höhe blieben die Erkrankungszifferm für je 5 Tage bis zum Ende Juli stehen, um dann Anfang August erneut steil abzufallen auf vereinzelte Fälle und in der Zeit vom 21. bis 25. August wieder den Nullpunkt zu erreichen. Die eigentliche Epidemiezeit der ersten Welle fiel also zeitlich genau mit dem Monat Juli zusammen. Wähıend in den lotzten 5 Augusttagen nur ein Fall von Influenza zu verzeichnen war, zeigte die Kurve in der ersten Hälfte des September wieder langsani steigende Tendenz, indem in je 5 Tagen 3, 7 und 12 Mann erkrankten. In der Zeit vom 16. bis 20. September kam es dann mit gleicher Plötzlichkeit wie jm Juli zum Ausbruch der zweiten Epidemie. Die Kurve schnellte üher $183 \mathrm{Er}-$ krankungen in der Zeit vom 16. bis 20. September auf 223 Erkrankungen in der Zeit rom 21. bis 25 . September, dem Höhepunkte der zweiten Welle, hinauf, fiel dann in den nächsten 15 Tagen bis 10 . Oktober wieder steil ab auf 63, um ungefähr auf dieser Höhe bis Ende Oktober stehen zu bleiben. In der ersten Novemberbälfte fiel sie dann wieder ziemlich steil weiter und von Mitte November ab löste sich die Epidemie in Einzelerkrankungen auf, um bis jetat nicht wieder aufzutreten. Die Massenerkrankungen der zweiten Welle umfassen also den Zeitraum von Mitte September bis Mitte November. Die genaueren Einzelheiten sind aus der Kurventafel zu entnehren.

Vergleicht man den Verlauf der Juli- und der Herbstepidemie, so ergeben sich ganz bedeutsame Untersehiede. Während die erste Welle im wesentlichen in 4 Wochen zum Abschluß kam, zog sich die zweite Welle über 8 Wochen hin, zeigte also einen viel ausgedehnteren Verlauf. Dementsprechend waren auch die Morbiditätsziffern sehr verschieden. Bei der ersten Epidemie erkrankten bei einer durchschnittlichen Iststärke von 7550 Mann 464, gleich einem Prozentsatz von 6.1 Prozent, bei der zweiten Welle dagegen bei einer durchschnittlichen Iststärke von 7826 Mann 1058 oder 13.8 Prozent. Um einen vergleichenden Maßstab für die Schwere des Verlaufs der beiden Wellen zu gewinnen, wurde einmal die Zahl der Lazarettkranken, dann die Zahl der Todesfälle einander gegenübergestellt. Bei der Juliepidemie waren von den 464 Erkrankten nur 71 oder 15.3 Prozent der Lazarettbehandlung bedürftig. Während der Herbstepidemie muBten von den 1058 Kranken nicht weniger als 551 also 52 Prozent dem Lazarett zugeführt werden. Noch deutlicher wird der ungleich schwerere Verlauf der 

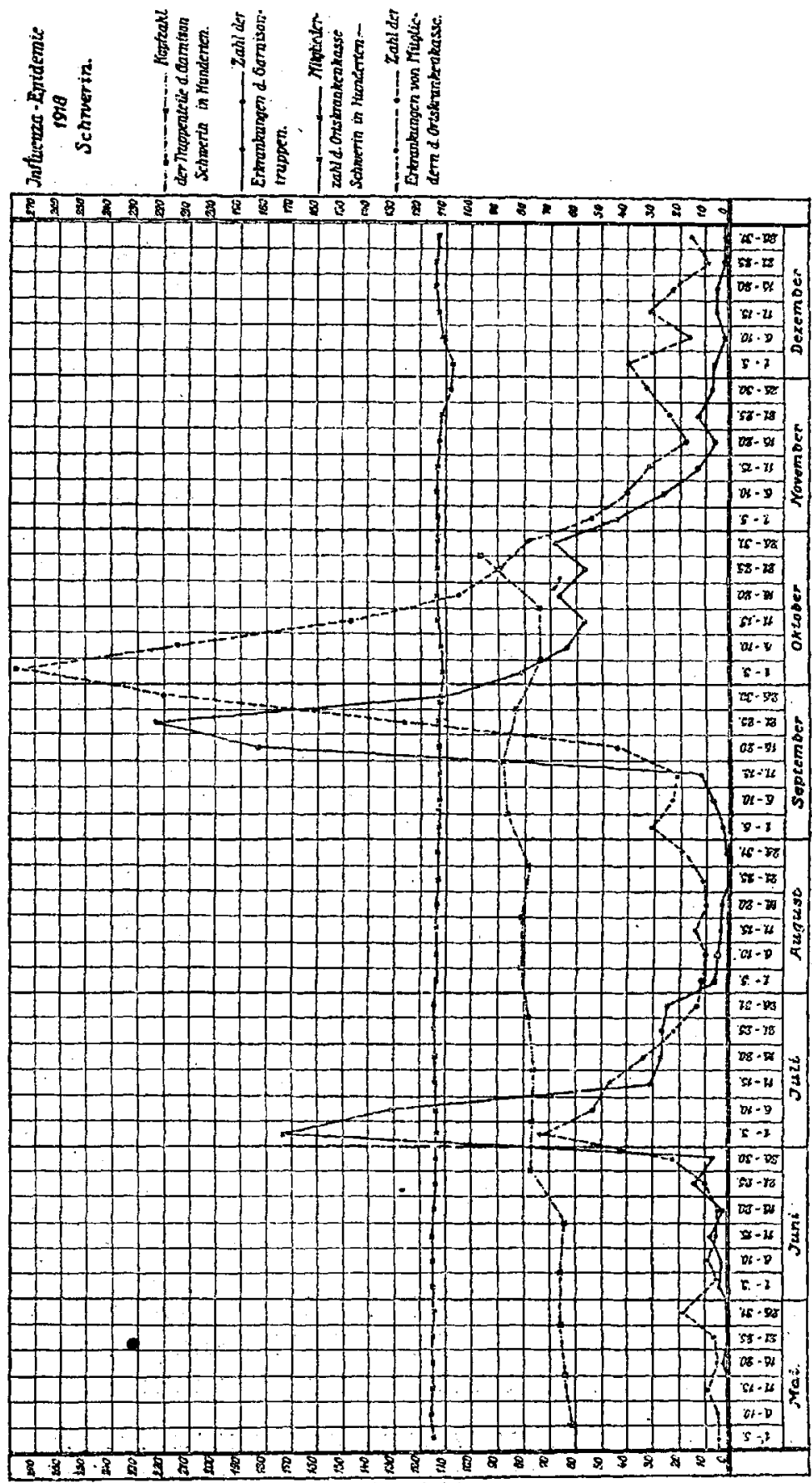
zweiten Welle durch die Mortalitätsziffern belegt. Von den 464 Erkrankten der ersten Epidemie starben nur 8, gleich einem Prozentsatz von 1. 7 Prozent, auf die Kopfstärke der Garnison verrechnet 1.06 Promille, während von den 1058 Kranken der zweiten Epidemie 95, also 9 Prozent, in bezug auf die Kopfstärke 12.14 Promille erlagen. Da die unkomplizierte Influenza nicht zum Tode führt, muß die hohe Mortalitätsziffer der zweiten Welle durch cin stärkeres Hervor treten der Sekundärinfektionen erklärt werden. Warum allerdings die Komplikationen bei der zweiten Epidemie so außerordentlich viel häufiger aufgetreten sind, darüber läßt sich nichts Sicheres sagen. Vielleicht hat die Jahreszeit hier eine Rolle gespielt, möglicherweise dadurch, daß die Eitererreger nach der sommerlichen Wärme in weiterer Verbreitung vorkommen.

Will man über die epidemiologischen Eigentümlichkeiten der Influenza nähere Aufschlüsse erzielen, so muß man auf ihren Verlauf in den kleineren Truppenverbänden näher eingehen. Zum Verständnis der weiteren Ausführungen sei vorausgeschickt, da $B$ die Gamison aus folgenden Truppenteilen bestand: Ersatzbataillon Inf.-Regts. 89 mit 4 Komp., Ersatzbataillon Landwehr-Inf.-Regts. 76 mit 3 Komp., II. Ersatzabteilung Feldartl.-Regts. 60 mit 5 Batterien und Fliegerbeobachterschule Görries mit 3 Komp. Der Verlauf der Influenza in den Kompagnien bzw. Batterien zeigte sowohl im Juli als auch im Herbst ganz enorme Verschiedenheiten. Bei der Juliepidemie entfielen von den 464 Erkrankten 152 auf die erste, 168 auf die zweite Kompagnie E/89, zusammen also 320, obwohl im Verhältnis zu ihrer Kopfstärke eigentlich nur 149 Erkrankungen nach dem Prozentsatz des Gesamtverlaufs für sie in Frage kämen. Dementsprechend hatte die erste Kompagnic eine Morbidität von 13 Prozent, die zweite eine solche von $131 / 2$ Prozent gegenüber einem Prozentsatz von 6.1 Prozent für die gesamte Garnison. Die Mortalität war besonders bei der ersten Kompagnie E/89 mit 41/2 Prozent der Erkrankten gegen 1.7 Prozent Gesamtdurchschnitt eine auffallend hohe. Von den 8 Todesfällen der Juliwelle gehörten 7 der ersten Kompagnie, 1 der. zweiten Kompagnie E/89 an, während alle anderen Truppenteilc keine Verluste an Toten hatten, obwohl sie mit 144 Erkrankungen an der Gesamtziffer von 464 beteiligt waren. Auffallend gering war die Zahl der Erkrankungen bei den übrigen Kompagnien von $\mathrm{E} / 89$ und bei der Artillerieabteilung. Während bei den ersteren beiden 0 Prozent bzw. 0.3 Prozent erkrankten, schwankten die Morbiditätsziffern bei den fünf Batterien IT. E/60 zwischen $0 \cdot 9$ und $2 \cdot 1$ Prozent gegen 6.1 Prozent Gesamtdurchschnitt.

Die Juliepidemie hat ihren Ausgang von der ersten Kompagnie E/89 genommen. Das Influenzavirus ist am 21. Juni in größerem Umfange da- 
durch eingeschleppt worden, daß an diesem Tage mehrere Hundert Manı der achtzehnjährigen Rekruten aus Berlin und Hamburg gleichzeitig mit rund 700 Rekruten aus Mecklenburg, wo bis dahin die Influenza noch nicht in epidemischer Verbreiturg aufgetreten war, neu eingestellt wurden, Es kam so eine große Anzahl Personen aus bereits verseuchten Gebieten mit solchen aus bisher freien Bezirken zusammen, so dab fïr die Ausbreitung der Seuche die gïnstjgsten Bedingungen gegeben waren. 5 Tage nach Einstellung der Rekruten erfolgten auch bereits Krankmeldungen in größerer Zahl, so daß ein ursächlicher Zusammenhang zwischen den Rekruteneinstellungen und dem Ausbruch der Influenza kaum bestritten werden kann. Wenn auch vereinzelte Influenzafälle bereits vor der Einstellung von den Truppen gemeldet waren, so ist die Annahme, daß die neuen Rekruten in ihrer Gesamtheit erst hier mit dem Influenzavirus in Beriihrung kamen, abzulehnen, da bei der Artillerieabteilung, wo ebenfalls vereinzelte Erkrankungen vorgekommen waren, am 21. und 22. Juni ziemlich umfangreiche Neueinstellungen von aus dem noch nicht verseuchton Mecklenburg stammenden Rekuten des Jahrganges 1900 erfolgten, ohne daß es hier zu Influenzaerkrankungen in bemerkenswerter Zahl gekommen wäre. Außerdem steht es keineswegs fest, ob die im Mai und Anfang Juni beobachteter! Fälle wirklich durch das Virus dex pandemischen Influenza hervorgerufen und nicht eigentliche „Grippe"-Fälle in des Wortes ursprünglicher Bedeutung waren. $\mathrm{DaB}$ die Epidemie ziemlich schnell von der ersten auf die zweite Kompagnie E/89 überging, findet seine Erklärung leicht dadurch, daß beide durch gleichzeitige Benutzung der Mannschaftseßräume und durch gleichzeitigen Besuch eines Vortrages am 27. Juni in innige Beruhrung zueinander kamen. Die Inkubationszeit läßt sich auf 4 Tage berechnen. Das Virus muB außerordentlich kontagiös gewesen sein und sich mit verblüffencer Schnelligkeit verbreitet haben. Für die Utbertragung ist wohl' lediglich der Kontakt von Mensch zu Mensch durch Tröpfeheninhalation verantwortlieh zil $\cdot$ machen.

Diese epidemiologischen Erfahrungen der Juliepidemie wurden in den wesentlichen Zügen durch die Herbstepidemie bestätigt. Was die Zahl der Erkrankungen anbelangt, waren die Hauptträger dieser Epidemie die erste Kompagnie E L/76 und die Fahrer-Batterie II. E/60. Bei der ersteren erkrankten bei einer durchschnittlichen Iststärke von 1365 Mann 522 oder 38 Prozent, bei der letzteren von 260 Mann 63 oder 24 Prozent, wăhrend die Morbidität während der zweiten Welle für die gesamte Garnison 13.8 Prozent betrug. Anch die erste Kompagnie E/89 hatte wieder eine hohe Erkrankungsziffer mit $141 / 2$ Prozent. Die Herbstepidemie ging ohne Zweifel 
von der ersten Kompagnie E L/76 und der Fahrer-Batterie II. E/60 aus. Diese beiden Truppenteile stellten am 11. September eine größere Anzähl 18 bis 20 jähriger Rekruten ein. Prompt wie bei der Juliepidemie erfolgter nach 5 bzw. 4 Tagen die ersten Krankmoldungen, und zwar sofort in ganz erheblicher Zahl. Bei der ersten Kompagnie E L/76 stammte der Frsatz zum Teil aus Mecklenburg, zum andern Teil aus den Bezirken Schneideniuhl, Deutsch-Krone, Neustettin. Nach übereinstimmenden Aussagen der Mannschaften aus letzteren Gebieten war dort die Influenza vor ihrer Einzichung zum Heeresdienst nicht aufgetreten. Sic konnten also noch nicht immunisiert sein, aber auch nicht den spezifischen K̇rankheitsstoff mitbringen. Gerade diese Mannschaften erkrankten zuerst und am ausgedehntesten, weshalb mit Sicherheit anzunehmen ist, $\mathrm{da} B$ der Infektionsstoff mit den aus den damals einmal durehseuchten Mecklenburg stammenden Rekruten enieut eingeschleppt wurde. Hierfür spricht auch des Verlauf der Seuche bei der Fahrer-Batterie II. E/60. In dieser Batterie waren während der ganzen Juliepidemie nur 4 Erkrankungen, vom 21. Juli bis zum Ausbruch der Herbstepidemie überhaupt keine Fälle von Influènza vorgekommen: Es müssen also hier zweifellos die neueingestellten, alle aus Mecklenburg stammenden Rekruten den verderblichen Keim mitgebracht haben. Wie bei der Juliwelle so mußte auch bei der Herbstepidemie auffallendsterweise wieder die erste Kompagnie E/89 der Seuche den Haupttribut an Toten zollen: Nicht weniger als 32.9 Promille der Kopfstärke, 22 Prozent der Gesaintzahl ihrer Erkrankten, 51 Prozent ihrer Lazarettkranken wurden durch die Epidemie dahingerafft! Auch bei der. Fahrer-Batterie II. E/60 und bei der Genesendenkompagnie E L/76 war der Verlauf sehr schwer: Bei der ersteren starben sogar 46.1 Promille des Mannschaftsbestandes 20 Prozent aller Erkrankten, 33 Prozent der Lazareitkranken. In krasisem Gegensatz zu dieser enorm hohen Mortalität steht der leichte Verlauf dei Herbstepidenie bei der ersten Kompagnie E L/76. Von den 522 Trkrankten starben hier nur 9; das bedeutet in bezug auf die Kopfstärke der Kompagnie nur 6.6 Promille, in bezug auf die Zahl der Errkankungen nur 1.7 Prozent, in bezug auf die Zahl der Lazarettkranken nur 3 Prozent! Bemerkenswert ist noch dei Verlanf in den Genesendenkompagnien. Hier war die Morbidität durchweg gering, im Mittel 3.3 Prozent gegen 13.8 Prozent Gesamtdurchschnitt der Garnison. Der geschwächte Körper der noch Schonungsbedürftigen zeigte also zum mindesten keine besondere Disposition für die Keime der. Influenza. Wurden sie aber von der Krankheit ergriffen, so zeigte sich ihre geringe Widerstandskraft in der außerordentlich hohen Letalität von 31 Prozenit.

Der extrem verschieden schwere Verlauf der Influenza in den im großen und ganzen als Wohngemeinschaften anzusprechenden kleineren Truppen? 
verbänden während der gleichen Epidemie bei ungefähr gleichem Menschenmaterial muß besonders auffallen. Wieder von der Voraussetzung ausgehend, $\mathrm{da}$ gewöhnljch nur die Komplikationen durch Misch- und Sekundärinfel. tionen tödlich enden, sehe ich zur Erklärung dieser Unterschiede in der Mortalität zwei Möglichkeiten: entweder waren die Eitererreger an Zahl lokal sehr verschieden oder sie wurden ebenfalls wie die Influenzaerreger durch Kontakt übertragen. Für die erste Möglichlkeit ließe sich vielleicht der schwere Verlauf der Influenza bei der ersten Kompagnic E/89 während beider Epidemiewellen verwerten, da die Kompagnie beide Mfale dieselben Quartiere innehatte. Sympathischer erscheint mir die Annahme der zweiten Möglichkeit. Es ist beispiclsweise folgende Entstehung und Entwickling einer Epidemie denkbar. In eine bisher vom Influenzavirus unberïhrte Wohngemeinsehaft wird das Kontagium der Influenza durch eine bestimmte Person hineingetragen. Erkrankt diese lediglich an der unkomplizierten Form, so wird sie das Virus auf die uibrigen disponierten Glieder der Gemoinschaft auch rein weiterübertragen. Falls nicht zufällig bei dem einen oder anderen Eitererreger komplizierend hinzutreten, wird es also in diesem Falle bei der prognostisch günstigen, reinen Form bleiben. Anders, wenn das Kontagium der Influenza durch eine bereits mit eitriger Bronchiolitis oder sogar pneumonischen Infiltraten behafteten Person eingeschleppt wird. Diese wird mit dem spezifischen Ansteckungsstoff auch gleichzeitig die Eitererreger übertragen und es bestelt natürlich hierbei eine sehr vicl höhere Wahrscheinlichkeit für eitrige Komplikationen als im ersteren Falle. Für die Infektiosität del Influenzamischinfektion sprechen auch allerlei Beobachtungen aus der Praxis. Rosenbaum teilt in einer kurzen Notiz nit, $\mathrm{da} ß$ sich bei genauer Beobachtung seines Lazarettmaterials immer mehr die Tatsache aufdrängte, daß die Pneumonien und Todesfälle durch Pneumonien sich in einzelnen Zimmern häuften. Als schließlich die Zimmer, in denen eine Pneumonie zum Ausbruch gekommen war, erst nach sorgfä]tiger mechanischer Reinigung und mehrtägigen Leerstelien von neuem mit Influenzikranken belegt wurden, nahm die Zahl der Pneumonien unter den durchschnittlich 120 Influenzakranken der Station plötzlich ab trotz unveränderter Behandlungsweise und unveränderter Schwere der Epidemie in der Stadt und Umgebung. Von den Allgemeinpraktikern ist vielfach die Erfahrung gemacht worden, daß die Influenza öfter familienweise besonders schwer verlaufen ist, eine Beobachtung, die ihre. Erklärung auch durch die Mitübertragung der Eitererreger infolge des innigen Kontakts der Familienglieder findet. Auch die Prägung des Ausdrucks ,, Kameradschaftsgrippe " entspringt wohl der Erfahrung, daß die Influenza in den einzelnen Kameradschaften cinen ziemlich gleichartigen Verlauf genommen hat, 
Aus diesen Erwägungen und Beobachtungen kann man wichtige Schlïsse fiir die Prophylaxe der Influenza ziehen. Auch bei Vermeidung von größeren Menschenansammlungen und der öffentlichen Verkebrsmittel wird man sich, wenn man seinem Tagewerk in gewohnter Weise nachgehen will, kaum zu Zeiten einer Pandemie gegen den ungemein verbreiteten Ansteckungsstoff der Influenza schützen können. Bei der für die reine Form der Influenza absolut günstigen Prognose ist dies ja auch weniger wichtig als die Verhütung der folgenschweren Sekundärinfektionen. Bei der außerordentlich hohen Empfänglichkeit des influenzakranken Organismus für die verschiedenen pyogenen Bakterien muß jeder Kranke unverzüglich zu seinem und seiner Umgebung Nutzen isoliert werden und am besten das Bett aufsuchen. Durch eine derartige Maßnahme, die in der Praxis bei gutem Willen in vielen Fällen dưchführbar ist, würden sicherlich zahlreiche Sekundärinfektionen und damit Todesfälle zu vermeiden sein. Auf eine gleichzeitig mit der Ubbertragung des Influenzavirus erfolgende Mischinfektion würde diese Maßnahme an sich keinen Einfluß haben, doch würden sich durch die Bettruhe nach den Erfahrungen der Praxis die Komplikationen häufiger auf eine Bronehiolitis obne schwerere Folgezustände beschränken lassen.

\begin{tabular}{|c|c|c|c|c|c|c|c|c|c|}
\hline & \multicolumn{3}{|c|}{$\begin{array}{c}\text { Morbidit ̈̈t } \\
\text { der }\end{array}$} & \multicolumn{3}{|c|}{$\begin{array}{l}\text { Letulität } \\
\text { der }\end{array}$} & \multicolumn{3}{|c|}{$\begin{array}{c}\text { Mortalität } \\
\text { der }\end{array}$} \\
\hline & $\begin{array}{l}\stackrel{0}{5} \\
\div \\
\end{array}$ & $\begin{array}{l}\stackrel{0}{\overline{0}} \\
\% \\
0\end{array}$ & 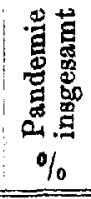 & 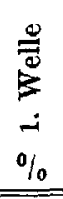 & $\begin{array}{l}\frac{0}{5} \\
\% \\
0 \\
0\end{array}$ & 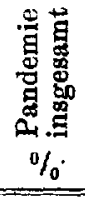 & 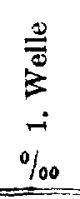 & $\begin{array}{l}\stackrel{9}{0} \\
\% \\
\% \\
\%\end{array}$ & 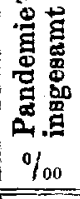 \\
\hline Garn & $6 \cdot 1$ & $18 \cdot 8$ & $19 \cdot 8$ & $1 \cdot 7$ & $9 \cdot 0$ & $6 \cdot 8$ & 1.06 & $12 \cdot 14$ & $13 \cdot 4$ \\
\hline Ortskrankenkasse & $3 \cdot 4$ & $15 \cdot 4$ & $18 \cdot 7$ & 1.8 & $1 \cdot 8$ & $1 \cdot 7$ & 0.44 & $2 \cdot 8$ & $\mathbf{3} \cdot \mathbf{3}$ \\
\hline Standesamtsbezirk & - & - & - & 一 & - & - & 0.43 & $4 \cdot 4$ & 4.8 \\
\hline ZnsammengefaRt & 4.5 & $14 \cdot 6$ & $19 \cdot 2$ & 1.6 & $4 \cdot 5$ & $3 \cdot 8$ & 0.52 & $5 \cdot 17$ & $5 \cdot 7$ \\
\hline
\end{tabular}

Für den Verlauf der Epidemie unter der Zivilbevölkerung der Stadt Schwerin im ganzen lassen sich keine statistischen Unterlagen verschaffen, da die Zahlen der Erkrankungen nicht bekannt sind. Da aber die Ortskrankenkasse mit rund 11300 Mitgliedern mehr als ein Viertel der Bevölkerung umfaßt, wird man die hier gewonnene Kurve der Erkrankungen auf die Stadt verallgemeinern dürfen. Beim Vergleich der Kurve der Garnison mit derjenigen der Ortskrankenkasse stellt sich heraus, daß beide Epidemiewellen nahezu gleichzeitig beginnen und gleichzeitig enden. Der Krankheitskeim ist meines Erachtens nach den hier gemachten Eufahrungen vom 
Militär auf die Zivilbevölkerung ihergegangen. Das Nachfolgen der Epidemic unter der Zivilbevölkerung ist allerdings in den Kurven nicht erkenntlich, da die Inkubationszeit nur wenige Tage beträgt und mein zahlenmäßiges Material aus praktischen Gründen fünftägig zusammengefaßt ist. Der Ansteckungsstoff hat sich in der Bevölkerung nicht so explosionsartig verbreitet wie beim Militär, wie das ja bei den ganz verschiedenen Wohn- und Lebensverhältnissen nicht anders zu erwarten war. Die erste Welle ist in der Zivilhevölkerung üherhaupt nicht recht durchgedrungen und mit ihren Erkrankungsziffern wesentlich, fast um die Hälfte hinter der Garnison zuriickgeblieben, während die zweite Welle beide ungeführ gleich stark befallen hat. Was die genaueren statistischen Ermittelungen bei der Ortskrankenkasse betrifft, so erkrankten während der ersten Welle von 11400 Mitgliedern 385 gleich 3.4 Prozent; es starben hiervon 5 oder 0.44 Promille der Mitglieder, 1.3 Prozent der Kranken. Die zweite Welle erfaßte von 11300 Mitgliedem 1744 glejch 15.4 Prozent mit einer Mortalität von 32 oder 2.8 Promille der Mitglieder, 1.8 Prozent der Kranken. Im Standesamtshezirk Schwerin mit einer Zivilbevölkerung von rund 35000 Köpfen starben in der Epidemiezeit vom 21. Juni bis 31. Dezember 193 an Influenza und Lungenentzündung. Da in dem gleichen Zeitraum 191725 Todesfälle an lungenentzündung vorkamen, wird man also 1918 insgesamt 168 Todesfälle gleich 4:8 Promille der Bevölkerung der Influen za zur Last legen könıen Auf die erste Welle entfielen hiervon 15 oder 0.43 Promille, auf die zweite 153 oder 4.4 Promille. Wie aus der beigegebenen Tabelle hervorgeht, war also der Verlauf der Epidemie bei den Truppenteilen ungleich schwerer, erklärlich durch die größeren Wohngemeinschaften mit ihren höheren Gefahren der Sekundärinfektionen.

Zu erörtern wäre noch kurz der Einfluß von Alter und Geschlecht auf den Verlauf der Influenza. Sowohl bei den Heeresangehörigen als auch in der Zivilbevölkerung war die Morbidität besondess in den Jahren um 20 herum auffallend groß, während die Altersklassen unter 15 und über 25 Jahren hiergegen merklich geringere Ziffern stellten. Nach dem höheren Alter zu nahmen die Zahlen der Frkrankungen stetig ab, doch ist hierbei zu bedenken daB die höheren Altersklassen in der Bovölkerung auch einen verhältnismäßig viel geringeren Prozentsatz ausmachen als die jüngeren. Z. B. umfabten 1910 die Altersklassen von 0 bis 15 Jabren 30.9 Prozent, von 16 bis $3024 \cdot 7$ Prozent, von 31 bis $4519 \cdot 1$ Prozent, von 46 bis $6014 \cdot 5$ Prozent und über 60 Jahre 10.8 Prozent der Gesamtbevölkerung Mecklenburgs. Aber trotz Berücksichtignng dieser Verhältnisse übertrafen die Morbiditätsziffern der Altersklassen nm 20 herum diejenigen der niedrigeren und höheren 
Stufen auch relativ um ein Beträchtliches. Anders verhalten sich die Mortalitătsziffern. In absoluten Zahlen stand wegen seiner hohen Morbidität natürlich auch hier das Alter um 20 herum weit voran. Doch zeigten die relativen Zahlen deutlich eine stärkere Gefährdung des höheren Alters. Faßte man beispielsweise bei der Ortskrankenkasse die Altersklassen von 14 bis 50 Jahren, und diejenigen über 50 zusammen, so ergab sich für die erstere Gruppe eine Sterblichkeit von 1.48 Prozent der Erkrankten, fur die letztere aber eine solche von 4.44 Prozent oder das dreifache. Die Beteiligung der Geschlechter war relativ ziemlich gleich, absolut überwog in der Zivilbevölkerung besonders in den Altersklassen von 16 bis 25 Jahren ganz außerordentlich (5fach) das wejbliche Gesehlecht, da die männliche Bevölkerung dieses Alters ganz überwiegend zum Heeresdienst eingezogen war.

Zuletzt sei noch die Frage der Immunität erwähnt. Von versehiedenen Seiten ist die Ansicht vertreten worden, daß die Influenza keine Immunität hinterläßt. Demgegenüber muß betont werden, daß während der. zweiten Epidemie nur sehr wenig Personen erkrankt sind, die schon von der ersten ergriffen waren. Z. B. berichten Hoffmann und Keuper, daß von ihrem $187 \mathrm{Kopf}$ starken Krankenbauspersonal nur 2 zum zweiten Male erkrankten. Auch hier wurde die Beobachtung gemacht, daB während der zweiten Welle die schon während der ersten Erkrankten meist verschont blieben. Ausnahmen kamen vereinzelt vor, fallen aber bei der großen Zahl der Erkrankungen gar nicht ins Gewicht. Man muß schon aus dem Grunde an einer erworbenen Immunität bei der Influenza festhalten, da man sonst gar nicht in der Lage wäre, bei der außerordentlich weiten Verbreitung des Infektionsstoffes ein Erlöschen der Pandemie zu erklären. Die Pandemie kommt lediglich dadurch zum Aussterben, daß die für die Influenza disponierten Personen erkranken und durch das Utberstehen der Krankheit immunisiert werden. Wie lange die Immunität dauert, entzieht sich meiner Beurteilung Doch halte ich die von vielen Seiten vertretene Ansicht, die Bevorzugung der jugendlichen Personen um 20 herum und das Zurücktreten des höhereıt Alters bei den Erkrankungen an Influenza mit einer während der Epidemie $1889 / 90$ erworbenen Inmunität erklären zu wollen, für nicht begruindet, da dann die Altersklassen von 11 bis 15 und 25 bis 30 Jahren prozentual gleiehe Morbidität wie die Stufen von 16 bis 25 Jahren aufweisen müßten, was aber bestimmt nicht der Fall ist. Die Bevorzugung eines bestimuten Alters durch die Influenza ist eben eine Eigenschaft, die sie mit vielen anderen Krankheiten wie z. B. Varizellen, akutem Gelenkrheumatismus, Poliomyelitis acuta teilt, für die wir aber noch keine Erklärung haben. 
Daß wir es bei der großen Pandemie des Jahres 1918 tatsäehlich mit einem großen Seuchenzug der "Influenza" zu tun haben, kann nach allem bisher Gesagten keinem Zweifel unterliegen. Es wäre aber endlich an der Zeit, die Begriffe Influenza und Grippe in ihre alten Rechte einzusetzen und den Namen "Influenza" für die pandemisch auftretenden Erkrankungen. den Namen "Grippe" für die im Winter und Friulhjahr bei uns endemisch wiederkehrenden influenzaartigen Erkrankungen zı reservieren.

\section{Ätiologie der Influenzia.}

Nachdem ich im vorstehenden die bakteriologischen, pathologisehanatomischen und epidemiologischen Charakteristika dor vorjährigen Influenzapandemie geschildert habe, halte ich die Grundlagen für eine vorurteilsfreie Betrachtung der Ätiologie für gegeben. Die Influenza lokalisiert sich primär im Respirationsuraktus, besonders in der Trachea, woran nach eigenen und anderen Beobachtungen kein \%weifel mehr bestehen dürfte. Auf Grund eingehender histologischer und bakteriologischer Untersuchungen und mit Verwertung der klinischen Symptome habe ich eine reinliche Scheidung der anatomischen Substrate der Influenza und ihrer Komplikationen vorgenommen. Um nicht von vormherein in ein falsches Falurwasser $z u$ geraten, habe ich bei dieser Abgrenzung die ätiologische Frage der Influenza selbst vollständig außer acht gelassen, sondern mich im wesentlichen von pathologisch-anatomischen und klinischen Gesichtspunkten leiten lassen: Dis Genese der Komplikationen einschließlich der eitrigen Bronchiolitis konnte hierbei bereits durch den regelmäßigen Nachweịs der Eitererreger und durch die bakteriologische Identifizierung derselben als solrhe abgetan werden. Ich kann also jetzt die Frage nach der Ätiologie soweit einengen; dab ich sage: Wodurch wird die katarrhalische 'Tracheitis, diese einzige, auch bei der ,reinen“. Influenza regelmäßjg wiederkehrende und dem spezifischen Erreger zuzuschreibende Verïnderung hervorgerufen? Meine eigenen Untersuchungen haben hier zu einem absolut negativen Ergebnis geführt. Ich habe auf und in der durch Abspiulen von Sekret befreiten Schleimhaut weder Bakterien noch als Chlamydozoen anzusprechende Granula gefunden und komme zu dem SchluB, daß ich den Erreger der spezifischen Tracheitis nicht gesehen habe.

Im Brenupunkt der Diskussion über die Ätiologic der Influenza steht nach wie vor der letzten Pandemie die Frage nach der ätiologischen Bedeutung der Pfeifferschen Bazillen. Obwohl ich nach meinen eigenen Untersuchungen nie auf den.Gedanken gekommen wäre, da.ß diese Bakterien 
eine spezifische Rolle bei der Influenza spielen könnten, erscheint es mir bei dem allgemeinen Interesse, das diese- Gegenstand erweckt hat, und bei dem Widerstreit der Meinungen dringend erforderlich, das gesamte Für und Wider eingehend zu erörtern und unter Zuhilfenahme meiner eigenen Erfahrungen kritisch gegeneinander abzuwägen, um so zu versuchen, zu einem abschließenden Uiteil in diesem Punkte zu gelangen. Ich werde dabei von den Untersuchungen Pfeiffers ausgehen, den Stand der Frage vor dem Ausbruch der vorjährigen Pandemie an Hand der Ausführungen Schellers im Handbuch der pathogenen Mihroorganismen von Kolle und Wassermann und der Darstellung Jochmanns kurz skizzieren und dann die Ergebnisse der Forschungen, die uns der letzte Seuchenzug in Deutschland gebracht hat, kritisch erörtern.

Bei der grundlegenden Bedeutung der Pfeifferschen Befunde gehe ich auf dieselben näher ein unter Zitierung hier besonders interessierender Stellen seiner Arbeiten. Nach Ansicht Pfeiffers „zeigt der Grippeauswurf sehr charakteristische Besonderheiten. Er ist von gelbgrüner Farbe, höehst zähe und klebrig und wird gewöhnlich in dicken, münzenförmigen Ballen entleert. Dabei ist er nicht selten höchst kopiös, so daß die Kranken in 24 Stunden mehrere $100 \mathrm{ccm}$ Sputum herausbefördern". Zur Untersuchung sollen sich die charakteristischen Eiterflocken oder Eiterballen am besten eigenen. In den Ausstrichpräparaten fanden sich die Bazillen meist in ungeheurer Zahl und in charakteristischer Anordnung in Haufen oder in Zügen. „Bei frischen noch fiebernden Kranken findet man die Influenzabazillen in den unter heftigen Hustenstößen aus den Bronchien expektorierten zähen sehaumigen Sputummassen häufchenweise frei in die schleimige Grundsubstanz des Sputums eingebettet, während die Eiterzellen die spezifischen Bakterien nur in geringer Menge enthalten. Beim Fortschreiten der Krankheit ändert sich das mikroskopische Bild des Auswurfs in charakteristischer Weise. Die Anzahl der freien Influenzabazillen nimmt ab, dafïr erseheinen die Eiterzellen geradezu vollgestopft mit den feinen Stäbchen, welche das Protoplasma in dichten Schwärmen erfüllen. Ist das akute Stadium des Influenzakatarrhes vorïber, der Kranke Rekonvaleszent, dann sieht man die überwiegende Mehrzahl der Stäbchen im Innern der Eiterzellen. In diesem Stadium gewahrt man an den Bazillen vielfach deutliche Degeneratiơnserscheinungen. Sie sind enorm schmal, färhen sich schlecht und zerbröckeln in feinsten molekularen Detritus." Besonders wichtig erscheint mir die Darstellung Pfeiffers über die Befunde am Leichenmaterial: „Schon grob anatomisch findet man in derartigen Ieichen sehr auffällige Verändenungen, die hauptsächlich in den Lungen lokalisiert sind. Dje letzteren zeigen 
sich in größerer oder geringerer Ausdehnung pneumonisch infiltriert. Dieśe Influenzapneumonie ist schon für das bloße Auge deutlich verschieden voin der gleichmäßigen lobären Hepatisation der kroupösen Pneumonie. Unischwer erkennt man, daß sie sich zusammensetzt aus einer ganzen Anzahl lobulärer Herde, die entweder durch lufthaltiges Gewebe getrennt bleiben oder auch wenigstens teilweise niteinander verschmelzen. So entstehen sckundär anscheinend lobäro Infiltrate, an denen man jedoch bei genanem Zusehei den so charakteristischen Aufbau aus getrennten Lobulärpneur:onien immer noch erkenuen kann. Trotzdem mögen häufig genug Verweclislungen mit kroupösen Lungenentziundungen vorgekommen sein. An den einzelnen lobulären Herden sieht man des öfteren noch eine weitere Struktur. In ihrem Zentrum hoben sich kleine stechnadelkopf- bis höchstens erbsengroße Partien durch eine graugelbliche Färlung von dem sie ungebenden dunkelroten Gewebe deutlich ab. Bei Druck anf die erkrankten Lungen ergießt sich aus den durehschnitteren Bronchien oder auch mitten aus dem infiltrierten Gewebe tropfenweise ein grün-gelblicher; dicker, sehr zäher Eiter, der sofort an das Sputum der lifluenzakranken erinne.t.

Um nun über die Infektionserreger ins klare an kommen, mub man die Untersuchung über den ganzen Bronchialbaum, vom Kehlkopf anfangend bis hinab in die Alveolen, ausdehnen. In Ausstrichpräparaten, die mit dem auf der Schleimhaut des Kehlkopfes und der Trachea haftenden Sekret angefertigt wurden, findet man gewöhnlich noch ein Genisch verschiedener Bakterienarten, Stıeptokokken, Fränkelsche Diplokokken usw., aber unter ihnen überwiegt hier schon regelmäßig der Influenzabazillus an Zalıl ganz gewaltig. In den größeren Bronehien werden die Beinengungen anderer Bakterien immer sparsamer; in den feineren mit eitrigem Inhalt gefültten Bronchialästen ist der Influenzabazillus Alleinherrscher, ebenso im Iungengewebe."

In bezug auf die pnounonischen Herde fährt Pfeiffer fort: „Durchmustelt man nun dieselben Stellen der Lungenschnitte in starker Vergrößerung, so erhält man äußerst frappante Bilder. In den Bronchien sieht man auf dem Epithel und zwischen dessen Zellen enorme Mengen winzig feiner Stäbchen, die sich besonders dort anhäufen, wo die Destruktionen des Epithelstratums deutlichex lervortreten. Man kam sie bis unter das Epithel in dichten Zügen verfolgen; in dem submukösen Bindegewebe dagegen kommen sie höchstens vereinzelt vor. Die Eiterzellen, die zwischen und auf den Flimmerzellen lagern, sind gleichfalls vollständig angefüllt mit denselben feinen Stäbchen, die sich bei Züchtungsversuchen als unzweifelhafte Influenzabazillen zu erkennen geben. Man kann sich nicht des Gedankens erwehren, da $\beta$ durch die Wucherung dieser Infektionserreger auf und in 
dem Epithel ein Reiz ausgeübt wird, welcher zur Hyperämie des submukösen Geweles und zur Anlockung zahlreicher Wanderzellen führt. Letztere gelangen durch ihre Lokomotion oder mit dem Säftestrom an die freie Oberfläche des. Bronchus, beladen sich dort mit den feinen Stäbehon und bilden so das charakteristische Schleim- und eitrige Sekret der Influenzabronchi tiden. Der ganze Prozeß stellt sich demnach als katarrhalische Eiterung in optima forma dar und erinnert durchaus, wenn man von der Differenz der Infektionserreger absieht, an die gonorrhoische Erkrankung der Harnröhren- und Konjunktivalschleimhaut.

Ganz ähnlich ist das Bild in den zentralen Partien der lobulären Influenzaherde. Auch hier sind die Rundze]len, welche das Gewebe erfüllen, geradezu überladen mit Scharen von Influenzastäbchen. Seltener findet man einzelne Bazillen oder kleine Gruppen derselben frei zwischen den Eiterkörperchen. In den Randzonen werden die bazillenhaltigen Zellen spärlicher; von anderen Mikroorganismen, Streptokokken, Fränkelschen Diplokokken sieht man in frischen Affektionen ebensowenig etwas in Schnitten, wie in den Ausstrichpräparaten.

Die katarrhalischen Prozesse der Schleimhäute haben eine ausgesprochene Neigung weiterzukricchen. So stejgt auch die Influenzabronchitis von der Nase oder dem Kehlkopf ausgehend in die Bronchien herab und erreicht per continuitatem fortschreitend das Lungengewebe. Unter Berücksichtigung dieses Verhaltens findet der lobuläre Aufbau der Influenzapneumonie seine ausreichende Erklärung. Jeder Infiltrationsbezirk ist eben in Zusammenhang zu denken mit einem erkrankten Bronchus, durch dessen Vermittlung erst die Krankheitsursache zu dem Lungengewebe den Zutritt erhält.

In den Leichen von Personen, welche an Influenzapneumonien gestorben sind, findet man nun, wenn der Tod auf der Höhe der Krankheit erfolgte, die eben beschriebenen pathologisch-anatomischen Zustände in voller Reinheit. War der Exitus, wie dies häufig der Fall ist, in einem späteren Stadium eingetreten, so ist das Bild, welches die Lungen darbieten, viel komplizierter und schwerer zu deuten. Man trifft dann in ein und derselben Lunge unter Umständen eine wahre Musterkarte von Veränderungen, die als verschiedene Ausgänge der Grippepneumonie sich darstellen."

Nach Pfeiffers Erfahrungen werden in der Rekonvalszens noch durch Wochen und Monate Influenzabazillen in ungeheuren Mengen in einzelnen Sputumballen ausgeworfen. Besonders lange beobachtete er Influenzabazillen bei Phthisikern mit Kavernenbildung. Er spricht hier von , ,chronischer Influenza der Phthisiker", da er beobachtet haben will, daß der 
Verlauf der Tuberkulose durch die Anwesenheit seiner Bazillen in der Regel ungünstig beeinflußt wurde.

Da Versuchstiere sich für die Influenzabazillen als nicht empfänglich erwiesen haben, konnte Pfeiffer also die spezifische Natur seiner Mikroorganismen nur auf ihrem fast regelmäßigen Nachweis in den Krankbeitsprodukten Influenzalranker und -Rekonvaleszenten grïnden.

Pfeiffer hat die Entdeckung seiner Influenzabazillen im Januar 1892 «nm ersten Male der Öffentlichkeit übergeben. Eine Nachprüfung seiner Befunde durch andere Untersucher an anderen Orten konnte also in größerem, Urufange erst zu einer Zeit einsetzen, wo die gro fe Pandemiewelle des Winters 1889/90 längst verrauscht war. An dem Material der kleineren Nachepidemien wurden die Pfeifferschen Untersuchungsergebnisse von einer Reihe namhafter Autoren bestätigt, doch fehlt es anch nicht an zahlreichen Forschern, die den Pfeifferschen Bacillus nur selten oder gar nicht fanden. Ich möchte die letzteren, vielfach negativen Befunde als keineswegs beweiskräftig für eine Stellungnahme gegen den Pfeifferschen Bacillus als spezifischen Erreger ansehen, da es absolut ungeklärt ist, ob die bei uns beobachteten, kleinen Epidemien influenzaartiger Erkrankungen ätiologisch mit den Pandemien identisch sind. Diese negativen Befunde scheiden meines Erachtens als Beweismaterial aus. Anders zu bewerten sind die positiven Befunde von Pfeifferschen Bazillen zu influenzafreien Zeiten. Bei Diphtherie wurden in Tonsillenabstrichen oder in bronchopneumonischen Herden $u$. a. von Leiner in 11 Fällen, von Auerbach in 12 Fällen, von Jehle unter 15 Diphtheriefällen 9 mal in Abstrichen, von Paltauf 2 mal, von Jochmann 3 mal in Lobulärpneumonien nach Diphtherie Pfeiffersche. Bazillen gefunden. Bei Masern konnte sie unter zahlreichen anderen Untersuchern Süß wein unter 21 Fällen 10mal, Liebscher unter 57 Fällen 11mal, Jehle unter 23 Füllen $18 \mathrm{mal}$, Joch man $\mathrm{n}$ bei 18 Masernsektionen $5 \mathrm{mal}$ in bronchopneumonischen Herden nachweisen. Nicht so häufig aber jmmerhin bemerkenswert ist das Vorkommen der Pfeifferschen Bazillen beim Scharlach. Bei Phthisikern hat Jochmann in 12 Fällen, Kliene berger unter 13 Fällen 8 mal Pfeiffersche Bazillen gefunden, ohne daß der Verlauf der Tuberkulose klinisch oder pathologisch-anatomisch Besondorheiten zeigte. Auch bei Fimphysematikern haben Ortner und Jochmann des öfteren Pfeiffersche Bazillen gefunden, „ohne daß das Krankheitsbild ein anderes Aussehen bot als bei gleichartigen Kranken mit fehlendem Influenzabazillenbefunde". Über das Vorkommen bei Keuchhusten sagt Jochmann: „In einem besonderen Verhăltnis steht der Keuchhusten zu den. Influenzabazillen. Hier konnte ich in meinen über drei Jahre ausgedehnten Untersuchungen nach- 
weisen, daß der Pfeiffersche Bacillus fast konstant im Pertussissputim vorkommt, und daß das nämliche Stäbchen auch fast stats die den Kouchhusten komplizierenden Bronchopneumonien verursacht, während es hei den andern infektiösen Kinderkrankheiten bald häufiger, bald seltener gefunden wird."

Durch die negativen Befunde an Pfeifferschen Bazillen bei influenzaartigen Erkrankungen einerseits und durch die verhältnismäßig zahlreichen positiven Befunde in epidemiefreien Zeiten bei vielen anderen Erkrankungen hat sich eine Reihe von Autoren schon vor der letzten Pandemie veranlaßit gesehen, die Pfeifferschen Bazillen als Erreger der Influenza abzulehnen. Scheller (1913) schreibt hieribel: „So findet Saquépée sogar, daß die Influenza keine bazilläre Erkrankung sei, Besançou und de Jong gláuben, daß die Influenza weder durch Influenzabazillen noch durch sonstige bekannte Erreger hervorgerufen werde, sondern dab unbekannte Erreger ätiologisch daran beteiligt sein müssen. Bernard gibt an, daß die Influenza hervorgerufen werden kann: erstens durch einen unbekannten Mikroben, zweitens durch Pneumokokken, drittens durch den Streptokokkus, viertens durch den Pfeiffer-Bacillus, fünftens dureh verschiedene Erreger, welche im normalen Respirationstraktus zu finden seien. Boix kommt zu der Ansicht, daß Influenza und Grippe eine einheitliche Erkrankung ist und daher durch einen Erreger hervorgerufen werden muß, sei es durch den Influenzabacillus oder durch noch unbekannte Krankheitserreger. Zu ähnlich absprechenden Urteilen kamen Curschmann, Ebstein, Klieneberger, Rosenthal und andere." Auch Kruse hat die Vermutung ausgesprochen, da $B$ der Influenzakeim zu den filtrierbaren Erregern gehöre. Wenn Scheller, ohne den Pfeifferschen Argumenten für die Spezifität seiner Bazillen neue Grïnde hinzufügen zu können, zu dem Schluß gelangt, „daß die R. Pfeiffersche Ansicht, daß der Influenzabazillus für die echte Influenza spezifisch ist, als bewiesen angesehen werden muB, und daß das in Bestätigung der Pfeifferschen Ansicht aufgestellte Wassermanns he Postulat: Wo Influenza, da Influenzabazillen zu Recht besteht", so möehte ich diese Folgerung nach den obigen Zusammenstellungen auch ohne Kenntnis der Forschungsergebnisse der letzten Pandemie mit einem Fragezeichen versehen. Jochmann gibt 1914, also unbeeinflußt durch die vorjährige Pandemie, uiber die ätiologische Bedeutung der Pfeifferschen Bazillen folgende Darstellung: „Der Pfeiffersche Bacillus vermag demnach für den menschlichen Organismus eine recht versehiedene Bedeutung zu gewinnen. Das Bild, das wir jetzt von ihm erhalten haben, entfernt sich ziemlich weit von dem, was Pfeiffer uns zuerst beschrieb. Zweifeln wir auch nicht an 
seiner ätiologischen Bedeutung für die epidemische Influenza, so haben wir ihn doch auch in verschiedenen anderen Rollen kennen gelernt. Er ist keineswegs absolut spezifisch für die epidemische Influenza, etwa wie der Gonococcus oder Tuberkuloseerreger für die Conorrhöe bzw. Tuberkulose. Er wird gelegentlich als Schmarotzer auf den. Tonsillen gefunden, sowohl bei Gesunden wie im Verlauf von Infektionskrankheiten, ferner in den Kavernen der Phthisiker und in Bronchiektasen, ohne daß dadurch das Krankheitsbild beeinflußt mu werden brauchte. Er vermag ferner bei Erwachsenen sowohl wie im Kindesalter leichtere und schwerere katarrhalische Bronchitiden und lobulär pneumonısche Prozesse auszulösen, so z. B.. im Verlaufe von Masern, Diphtherie und Keuchhusten, ohne daB dabei sonst irgendwelche Erseheinungen ausgeprägt wären, die zu der klinischen Diagnose Influenza Veránlassung geben. Man sollte deshalb in solchen Fällen davon Abstand nehmen, von "Komplikationen mit Influenza" zu sprechen, sondern lieber von Mischinfektion mit dem Pfeifferschen Bacillus reden und die Bezeichnung ,Komplikation mit Influenza“ für Fälle mit wirklich klinischer Influenza reservieren."

Betrachtet man ohne Voreingenommenheit diese Forschungsergebnisse, wie sie sich uns seit der Beschreibung des Pfeifferschen Bacillus 1892 und vor der Pandemie 1918 darbieten, so muß man zu der Überzeugung gelangen, dab eine allgemeine Anerkennung der spezifischen Natur der Pfeifferschen Mikroorganismen keineswegs erzielt worden ist, und daß ihre ätiologische Stellung überhaupt nur auf schwachen Füßen steht, da sie ausschließlich mit ihrem Vorkommen in den Krankheitsprodukten bei Influenza begründet wird. Auf jeden Fall muß betont werden, daß ein klarer Beweis für dieSpezifität des Pfeifferschẹn Bacillus vor der letaten Pandemie nicht er bracht werden konnte, da von dem Vorkommen bestimmter Bakterien in einzelnen Krankheitsprodukten noch nicht auf jhre ätiologische Bedeutung für die Krankheit als Ganzes geschlossen, geschweige denn, daß dieser Umstand als ein Beweis gedeutet werden darf. Gerade dje Influenza selbst liefert uns hierfür das beste Beispiel. In dem Blute und den inneren Organen der Influenzaleichen habe ich in 90 Prozent der Fälle Streptokokken nachgewiesen und doch haben sie mit dem spezifischen Virus nicht das geringste zn tun. Ich werde anf die Befunde Pfeiffers und seiner Nachuntersucher weiter unten noch kritisch näher eingehen, hier aber erst nochmals die Feststellung unterstreichen, daß eine einwandfreie, umfassende Nachprüfung der gesamten ätiologischen Fragen nur zu Zeiten einer zweifelsfreien Pandemie der Influenza geklärt werden können, wozu uns also seit 1892 zun erstenmal das vergangene Jahr mit sainem riesigen Seuchenzuge Gelegenheit gegeben hat. 
Was hat uns nun die neve Forschung in dieser Beziehung gebracht? Über verhältnismäßig zahlreiche positiva Befunde an Pfeifferschen Bazillen in Kranken- und Sektionsmaterial berichten v. Bergmann, Bonhoff, Dietrieh, E. Fränkel, E. Fraenkel, Friedberger und Konitzer, Fromme, Herzog, v. Hoesslin, Hübschmann, Korbseh, Leichtentritt, Mahlo, Oeller, Ohlsen, R. Pfeiffer, Schwermann, Simmonds, Sobernheim und Novakovié, Uhlenhuth, Zeißler. Spärliche oder nur vereinzelt positive Befunde hatten Becher, Berblinger, Busse, Deussing, Fürst, Gruber und Schädel, Hirsehbruch, Hoffmann und Keuper, Kisskalt, Kossel, Loewenthal, F. Meyer, Neufeld und Papamarku, Schiemann, Schmorl, Siegmund, Silbermann. Vollkommen negative Untersuchungsergebnisse erzielten Bernhardt, Binder und Prell, Fischer, Goldschmidt, Hesse, Klewitz, Kocpchen, Lämpe, Mandelbaum, K. Mayer, Schöppler, Selter. Nach meinen eigenen Beobachtungen muß ich mich dor mittleren Gruppe mit spärliclien Befunden einreihen. Die von so außerordentlich vielen Seiten gemeldeten spärlichen und negativen Befunde in den Krankheitsprodukten bei der letzten Pandemie bedeutet einen schweren Schlag gegen die ätiologische Stellung der Pfeifferschen Bazillen. Es ist außerordentlich interessant zu verfolgen mit welchen Argumenten die Anhänger Pfeiffers, die natïrlich fast atsschließlich aus der ersteren Gruppe hervorgehen, die mit der spezifischen Natur des Pfeifferschen Bacillus in krassem Widerspruch stehende Kluft zwischen der großen Zahl positiver und der noch größeren Zahl spärlicher und negativer Befunde zu ïberbrücken versuchen.

Der Haupteinwand gegen die negativen Untersuchungsergebnisse wird aus der Schwierigkeit der Kultur der Pfeifferschen Bazillen, insbesondere aus ihrer Launenhaftigkeit und den liohen Anspriichen an das Nährbodenmaterial hergeleitet und im Verein hiermit die Unerfahrenheit und mangelnden Kenntnisse der jüngeren Bakteriologen wenigstens für einen Teil der negativen Befunde verantwortlich gemacht. In der langen Reihe der Antoren, die über spärliche und negative Befunde berichten, dürften sich meines Erachtens genügend Namen befinden, die den letzten Einwand̆ entkräften. Anders verhalt es sich mit der Schwierigkeit der Nährbodentechnik. Ich gebe ohne weiteres zu, daß der Nachweis der Pfeifferschen Bazillen durch Kultur einige Übung erfordert, und daß nach den Mitteilungen aus der Literatur Fälle vorkommen können, wo der Nachweis der Bazillen infolge Untauglichkeit der Nährböden nicht gelungen ist. Es darf aber nicht übersehen werden, da.b sich unter den Autoren mit negativen Kulturergebnissen Forscher befinden, die mit reichen Kenntnissen und Erfahrungen in diesen 
einschlägigen Fragen an die Arbeit gegangen sind. Dann ist weiter zu bedenken, daß wohl von keinem der Untersucher versäumt worden ist, auch den Nachweis der Pfeiffeıschen Bazillen durch das gefärbte Ausstrichpräparat zu erbringen. Wenn die klassische Beschreibung der Bazillenbefunde im Sputum und im Bronchioleneiter, wie Pfeiffer sie gegeben hat und wie ich sie oben zitiert habe, allgemein zu Recht besteht, so ist es meiner Ansicht nach gänzlich ausgeschlossen, daß auch ein bakteriologischer „Anfänger": derart charakteristische Bilder, wie sie in jedem Lehrbuch beschrieben waren, hätte übersehen können. Es wird aber immer wieder betont, daß weder in Ausstrichpräparaten noch dureh Kultur der Nachweis der Bazillen gelungen ist. Was meine eigenen Beobachtungen betrifft, so habe ich bereits am Anfang meiner Ausführungen zu dieser Frage Stellung genommen. Ich wiederhole, daB ich bereits im Beginn der ersten Epidemie Reinkulturen von Pfeifferschen Bazillen erzielte, daB ich sowohl durch Fortziüchtung von Reinkulturen als auch von Zeit zu Zeit durch Neuzüchtung aus Untersuchungs material die Brauchbarkeit meiner Nährböden bestätigen konnte, daß ich stets auch gefärbte Ausstriche untersucht habe und daß die Kultur stets die mikroskopischen Befunde dieser Ausstriche bestätigt hat. Ich behaupte für mein Material, daß in der weitaus größeren Zahl der Fülle Pfeiffersche Bazillen nicht nur nicht gefunden, sondern auch in der Tat nicht vorhanden waren.

Eine andere Erklärung für die sich widersprechenden Befunde sehen viele Untersucher in der falschen Auswahl des Ausgangsmaterials. Es ist dabei aber überraschend, wie sehr sie sich selbst in den guten Ratschlägen widersprechen. Der eine empfiehlt nur das glasige, nicht eitrige Sputum zu nehmen; Pfeiffer und andere ziehen gerade den eitrigen, gelblichgrünen Auswurf vor. Der eine erwartet nur positive Befunde von Pfeiffersehen Bazillen beim Krankenmaterial, während Pfeiffer und andere sie ihm bis zu 100 Prozent aus dem Bronchioleneiter von Leichenmaterial zuichten. Bei derartigen Widersprïchen richtet sich diese Erklärung selbst.

Die überaus verschieden lautenden Angaben über die Befunde an Pfeifferschen Bazillen lassen sich in Wirklichkeit nur dadureh erklären, daß ihre lokale Verbreitung ganz außerordentlich geschwankt hat. Der Beweis hierfür kann erbracht werden. Vergleicht man nämlich die Befunde der verschiedenen Untersucher aus verschiedenen Laboratorien an den gleichen Orten, so ist man überrascht über die weitgehende Übereinstimmung derselben. Soweit ich es an Hand der mir zur Verfügung stehenden Literatur habe feststellen können, ist es nie vorgekommen, daß am gleichen Orte der eine Untersucher zahlreiche positive, der andere nur vereinzelte positive 
oder negative Befunde hatte. So wird nur über zahlreiche positive Befunde berichtet beispielsweise aus Hamburg von Fraenke1, Simmonds, OIsen und Zeißler, aus Leipzig von Herzog, Hübschmann und Oeller, aus Breslau von R. Pfeiffer und Leiohtentritt, aus Marburg von v. Bergmann und Bonhoff. Spärliche oder negative Befunde werden übereinstimmend gemeldet aus Berlin von Neufeld und Papamarku, F. Meyer, Loewenthal, aus Könjgsberg von Selter und Klewitz, aus Dresden von Schmorl und Lämpe, aus München von Mandelbaum und Schöppler, aus Frankfurt von Kolle, Goldschmid und Fischer, aus Kiel von Ki sskalt und Berblinger. Diese für die einzelnen Orte übereinstimmenden Angaben können keinen Zweifel mehr daran beștehen lassen, daß nicht Technik und Schulung der Untersucher, sondern die Verschiedenheiten in der lokalen Verbreitung der Pfeifferschen Bazillen die sich widersprechenden Resultate in ihrem Nachweis erklären. Die Pfeifferschen Bazillen sind vielenorts gar nicht, an anderen selten, an wieder anderen sehr zahlreich aufgetreten. Mit dieser Feststellung ist die einzige, an sich schon schwache Stuitze, die Pfeiffer der ätiologischen Bedeutung seiner Mikroörganismen geben konnte, in Trümmer gegangen.

Fromme, Levinthal, Neufeld und Papamarku, Sobernheim und Novakovié haben bei Agglutinationsprüfungen spezifische Agglutinine für Pfeiffersche Bazillen in einer beschränkten Anzahl von Fällen im Kranken- und Rekonvaleszentenserum nachweisen können und wollen diesen Befund für die Ätiologie dieser Bazillen verwerten. Dementgegen stehen aber die Angaben von Leichtentritt, Oeller, Uhlenhuth, die auch im Normalserum Agglutinine feststellten und so zu keinem eindeutigen Resultat kamen. Auch Fürst berichtet, daß von 3 Influenzastämmen nur 1 mit dem Serum von Kranken spezifische Agglutination zeigte, während die beiden andern wenig oder gar nicht beeinflußt wurden. Mit diesen $\mathrm{Br}$ gebnissen ist nicht viel anzufangen, zumal auch ein Auftreten von Agglutininen im Krankenserum erfolgen kann, wenn die betreffenden Bakterien lediglich eine Rolle als Sekundärerreger spielen, sofern sie eben nur pathogene Wirkungen entfalten und dadurch den Körper zur Reaktion veranlassen. Für die spezifische Natur der Pfeifferschen Bazillen dürften nur größere Versuchsreihen von eindeutig positiven Agglutinationsergebnissen zu verwerten sein, die bei einem Krankenmaterial aus Gegenden erzielt wurden, in denen Pfeiffersche Bazillen nicht vorkamen. Und auch das würde noch nicht beweisend sein, wie die Proteusagglutination bei Fleckfieber zeigt.

Ist so das Wenige, das für den Pfeifferschen Bazillus als ätiologisches Moment zu sprechen schien, hinfällig geworden, so können außerdem noeh 
gewichtige Gründe gegen seine spezifische Bedeutung ins Feld geführt werden. Sein Fehlen in den Krankheitsprodukten der Influenza und selbst ihrer Komplikationen an vielen Orten während einer weit ausgebreiteten Pandemie gerade bei seinem zahlreichen Auftreten in anderen Gegenden ist ein glatter Beweis gegen seine spezifische Natur. Wie Hübschmann aus dem Gedankengang Oellers, der die Influenza als akut ablaufende, durch Auflösung der spezifischen Erreger entstehende Toxikose auffaßt eine Ansicht, der ich mich im wesentlichen anschließe -, folgern kann, daß durch die schnelle Zerstörung der Bakterien die vielenorts negativen Befunde an Pfeifferschen Bazillen zu erklären seien, ist mir unverständlich, da die von zahlreichen Autoren sogar im Leichenmaterial bis zu 100 Prozent erhobenen positiven Befunde dieser Theorie völlig den Boden entziehen.

Ein weiterer Umstand, der gegen den Pfeifferschen Bazillus als spezifischen Erreger spricht, ergibt sich aus dem epidemiologischen Verhalten der Influenza. Es ist gänzlich mverständlich, daß ein zu epidemiefreien Zeiten so weit verbreiteter Keim wie der Pfeiffersche Bazillus urplötzlich zıI einer großen Pandemic Veranlassung geben kann. Die Influenzapandemie ist nicht bei uns entstanden, sondern ihr Zug beweist, daß der Kcim der Seuche, die wahrscheinlich in Spanien zuerst aufgetreten ist, von auswärts bei uns eingeschleppt wurde. Wollte man den Pfeifferschen Bazillus als das spezifische Kontagium anerkennen, so stände man vor der paradoxen Tatsache, daß derselbe Keim, der bei uns in weiter Verbreitung unter zur Influenza disponjerten Individuen nicht zur Infektion fühtte, von auswärts hereingebracht eine gewaltige Pandemie verursachen konnte. Diesen Gegensatz durch Virulenzverschiedenheiten der Frreger in verschiedenen Ländern erklären zu wollen, dürfte wohl keinem vorurteilsfreien Forscher genügen.

Zum Schluß führe ich noch die Ergebnisse der pathologisch-anatomischen Untersuchungen als Gegenbewels an. Pfeiffer selbst hält für den Nachweis seiner Bazillen in erster Linie den gelblichgrünen, gewöhnlich in dicken münzenförmigen Ballen entleerten Morgenauswurf für geeignet. Beim Leichenmaterial hat or sie ganz überwiegend im Bronchioleneiter und in den pnetlmonischen Infiltraten gesehen. Während der letzten Pandemie sind diese Befunde durch zahlreiche Autoren, die die Bazillen in größerer '/ahl naclıweisen konnten, bestätigt worden. Daß ihr Nachweis auch in Trachealschleim, der ja sicherlich bei der Bronchiolitis zum mindesten teilweise aus aufgehustetem Bronchioleninhalt besteht, ebenfalls gelungen ist, ist nicht weiter zu verwundern. In und auf der durch Abspülen von Sekret befreiten Schleimhaut ist mir aber der Nachweis nicht gelungen und auch in der Literatur habe ich hierüber keine näheren Angaben gefunden. Wo bei 
meinem Material überhaupt Pfeiffersche Bazillen vorhanden waren, habe auch ich sie hauptsächlich im Bronchioleneiter und in dem eitrigen Alveoleninhalt der pneumonischen Herde nachweisen können. Von andern Untersuchern sind ferner Pfeiffersche Bazillen zum Teil in Reinkultur als Erreger eitriger Meningitiden, von Endokarditiden und anderen Prozessen im Verlaufe der Influenza gefunden worden. Ich selbst habe sie aus einem Weichteilabszeß in Reinkultur erhalten. In seltenen Fällen sind sie auch aus dem Blut und inneren Organen geziichtet worden. Aus all diesen Angaben geht hervor, daß die Pfeifferschen Bazillen nur solche pathologischen Prozesse ausgelöst haben, die ich oben bereits als Komplikationen der Influenza gekennzeichnet habe. Die Prozentzahlen über positive Befunde an Pfeifferschen Bazillen in Sputumproben sind insofern irreführend, als hierbei unwillkürlich schon dadurch eine besondere Auslese der Kranken für die Untersuchung erfolgt ist, als reichlicher, insbesondere eitriger Auswurf, den Pfeiffer selbst empfiehlt, bei del reinen Form der Influenza ja gar nicht vorhanden, sondern schon ein Zeichen von Komplikationen ist. Wenn also angegeben wird, daß Pfeiffersche Bazillen in 100 Prozent der Fälle im Sputum gefunden sind, so heißt das mit anderen Worten in 100 Prozent von fast ausschließlich mit Komplikationen verlaufenden Fällen.

Der Pfeiffersche Bazillus spielt also bei der Influenza genau dieselbe Rolle, in der wir ihn auch z. B. bei Masern und Keuchhusten wiederfinden, und wir müssen ihn deshalb ganz allgemein als menschenpathogenen Erreger von sekundären Komplikationen im Verlauf von ätiologisch ganz verschiedenen Kranlkheiten ansprechen, der auch gelegentlich als Saprophyt auf den Schleimhäuten angetroffen wird. Den Namen Influenzabazillus trägt er zu Unrecht.

Nachdem so die ätiologischen Forschungsergebnisse der Pandemie 1918 die bisher herrschenden Anschauungen über das spezifische Kontagium der Influenza umgeworfen haben, drängt sich von selbst die Frage auf, was sie uns als Ersatz für die Pfeifferschen Bazillen an positiven Werten Neues gebracht haben. Binder und Prell berichten als ätiologisch bedeutungsvoll über ,,in größeren Gruppen angeordnete, rundliche Gebilde" vorwiegend in den Saftspalten um die Gefäße herum. Sie wurden in Lunge, Trachea und Milz gefunden. Binder sagt von ihnen: „Zunächst glaubte ich an eine intrazelluläre Lagerung, doch belehrten mich stärkere Vergrößerungen, daß dies nicht der Fall zu sein scheint." Die Größe der Körnchen war erheblich kleiner als Kokken. Sie lagen in einem deutlich von der Umgebung abgrenzbaren Substrat eingebettet in größeren Komplexen bis zu $30 \mu$ Länge beisammen. Gegen die Gramfärbung verhielten sie sich negativ. Ich habe 
diese Angaben nachgeprüft und ebenfalls besonders in Lunge und Leber derartige Befunde erheben kö̈nen, doch gebe ich ihnen eine ganz andere Deutung. Die Körnchenkomplexe sind meiner Ansicht nach langgestreckte, in del äußeren Form den Fibroblasten gleiche Zellen mit starker Granulierung, die lediglich im Bindegewebe vorkommen, und zwar an Stellen, wo dasselbe entzïndliche Reizung zeigt. Diese Zellen kommen aber nicht nur bei der Influenza vor, sondern ich habe sie in gleicher Weise auch bei anderen mit Bindegewebsneubildung einhergehenden Prozessen wiedergesehen, u. a. bei chronischer Endometritis und in gewöhnlichem Granulationsgewebe. Für eine ätiologische Bedeutung der von Binder und Prell beschriebenen Gebilde liegen keinerlei Anhaltspunkte vor.

v. Angerer und Prell haben aus dem Blut Influenzakranker in Traubenzuckerbouillon überaus feine, in wilder Molekularbewegung befindliche Körperchen gezüchtet, die negative Gramfärbung zeigen. Prell hält sie für identisch mit den von ihm beschriebenen Körnehen im perivaskulären Bindegewebe. Man kann diese Züichtungsergebnisse gar nicht vorsichtig genug beurteilen, da ähnliche Angaben auch für andere Erkrankungen bereits vorliegen und die gleichen Befunde auch aus Normalserum erzielt sind. Kronberger. sagt hierzu: „Langjährige Untersuchungen mit Blutkulturen haben mir den Beweis geliefert, daß wichtige Strukturelemente der normalen Säugetiererythrozyten Granula sind, die sich in gewissen Nährmedien isolieren und zu Massenkulturen weiterentwickeln lassen." Er bemerkt weiter, daß diese Granula färberisch und morphologiseh nicht von den bei Influenza beschriebenen getrennt werden können und nimmt an, da $B$ es sich auch hier um normale Erythrozytengranula handelt, da Olsen sie auch ans dem Bhute njeht Influenzakranker hat züchten können. Naegeli gibt in seiner Blutdiagnostik über diese Körperchen folgendes an: ,In jedem Blut beobachtet man auch feine Körnchen mit lebhaft amöboiden Bewegungen. Entweder sind diese Gebilde einzeln und in der Größe sehr variabel, oder aber in kleinen Ketten angeordnet. H. F. Müller hat auf diese Hämatokonien oder Blutstäubchen zuerst aufmerksam gemacht.": Möglicherweise sind auch diese Hämatokonien mit den Körperchen von Angerer und Prell identisch. Wir sind jedenfalls weit entfernt davon, den durch Traubenzuckerbouillon kultivierten Gebilden irgendwelche spezifisch-ătiologische Bedeutung zuerkennen zu müssen, da auch die im weiteren noch zu erörternden Infektionsversuche mit bakterienfreien Filtraten nicht auf ihre Spezifität schließen lassen.

Kruse, der u. a. schon vor der letzten Pandemie die Vermutung ausgesprochen hatte, daß der Influenzakeim zu den filtrierbaren oder unsicht- 
baren Erregern gehöre, ist es während der ersten Welle 1918 mit filtrierter Nasenspülflüssigkeit aus einém Influenzafall bei einigen seiner Zuhörer nicht gelungen, die Krankheit hervorzurufen. Selter entnahm bei 5 Patienten mit frischen Krankheitserscheinungen an Tüpfern Schleim der hinteren Rachenwand und ließ die Patienten mit Kochsalzlösung gurgeln. Gurgelwasser und den aus den Tüpfern mit Kochsalzlösung ausgeschïttelten Rachenschleim filtrierte er durch Berkefeldfilter. Das durch Spray zerstäubte Filtrat wurde von ihm und einer Hilfsassistentin eingeatmet. Bei ihm selbst trat am anderen Morgen Schnupfen mit Kopfschmerzen olme Fieber auf; am Abend waren die Erscheinungen verschwunden. Die Assistentin klagte am nächsten Tage iiber Kopfschmerzen und große Mattigkeit; am übernächsten Tag nach guter Nacht Kopfschmerz und $37 \cdot 6^{0}$ Temperatur, Mattigkeit und starke Schmerzen in Kniegelenken und Beinen. Nach Mittagsruhe und $1 \mathrm{~g}$ Aspirin bessert sich das Befinden; gegen Abend treten wieder Kopfschmerzen auf. In der folgenden Nacht wacht sie mit Schüttelfrost auf, danach starkes Schwitzen. Am nächsten Morgen nur noch geringe Kopf- und Gliederschmerzen und noch einige Tage Mattigkeit. Leschke konnte bei sich und einigen anderen Personen, nachdem eine ganze Reihe von Versuchen mit Sputumfiltraten fehlgeschlagen waren, mit einem Filtrat von Lungensaft durch Einatmung nach Zerstäuben typische und objektiv nachweisbare Krankheitserscheinungen der Influenza mit Fieber bis zu $40^{\circ}$ hervorrufen. Der Ausbruch der Krankheit erfolgte am gleichen oder folgenden Tage der Infektion. Fe jes stellte Versuche mit Affen an. Er injizierte Berkefeldkerzenfiltrate von Influenzasputum nach Sterilitätsprüfung subkutan auf zwei Makakusaffen und auf zwei Paviane. Das Ausgangsmaterial der Filtrate war in jedem Versuch ein anderes. In jedem Falle wurde ein Kontrolltier mit dem gleichen Filtrat geimpft, das aber vorher 1 Stunde auf $65^{\circ}$ erwärmt worden war. Alle vier Versuchstiere starben unter den pathologischen Erscheinungen einer hämorrhagischen Sepsis, alle vier Kontrolltiere blieben vollkommen gesund. Friedberger und Konitzer haben Infektionsversuche an 26 Personen mit durch Kerzen filtriortem Sputum von frischen und älteren Influenzafällen, sowie mit filtriertem Lungensaft und filtrierten Exsudaten frisch Verstorbener nach vorhetiger Sterilitätsprïfung angestellt, indem sie das zerstäubte Filtrat inhalieren ließen. Obwohl 7 Personen zweimal, 1 sogar fünfmal dem Spray ausgesetzt wurden, trat bei keinem der Fälle in der Folgezeit Fieber auf. Fiinf von den Versuchspersonen hatten vorher Influenza durchgemacht, die anderen stellten es bestimmt in Abrede.

Die Versuche von Selter können wegen ibrer geringen objektiven Krankheitserscheinungen keinen Anspruch auf Beweiskraft erheben. Die 
Ergebnisse von Leschke und Fejes auf der einen Seite und von Kruse und besonders von Friedberger auf der anderen lassen noch kein abschließendes Urteil über ein filtrierbares Virus der Influenza zu.

Soweit sich die bisherigen Forschungsergebnisse der letzten Pandemie übersehen lassen, sind wir der Klärung der Ätiologie der pandemischen Influenza um nichts näher gekommen. Wir müssen mehr als zuvor mit dem Influenzavirus als einer gänzlich unbekannten Größe rechnen.

\section{Zusammenfassung.}

Die Influenza ist eine durch einen noch unbekannten Lrreger hervorgerufene, in wenigen Tagen unter dem Bilde einer Toxikose akut verlaufende Infektionskrankheit von enormer Kontagiosität, die von Zeit zu Zeit in großen Seuchenzügen ganze Erdteile überzieht und vorwiegend jugendliche Personen erfaßit. Die ẗbertragung erfolgt unmittelbar von Mensch zu Mensch durch Tröpfcheninhalation. Das unbekannte Kontagium setzt sich primär in den Sehleimhäuten des Respirationstraktus, speziell in der unteren Trachea, fest und ruft hier eine katarrhalische Entzündung mit Epithelverlust ohne stärkere Selretion hervor. Dureh Toxinwirkung und vielleicht auch durch Übertritt der Erreger ins Blut entsteht eine ausgesprochene Neigung zu Blutungen in den Schleim- und serösen Häuten. Das Virus schafft speziell in den Bronchiolen einen locus minoris resistentiae für die verschiedensten pyogenen Bakterien, insbesondere für Streptokokken und Pfeiffersche Bazillen und setzt auch die Abwehrkraft des Organismus im ganzen gegen diese Infektionen herab, so daß es im Verlauf und im Anschluß an die Influenza relativ häufig zu Komplikationen eitriger Natur besonders in den Lungen und za Sepsis und Pyämie kommt, wodurch die an sieh absolut günstige Prognose der Influenza sehr verschlechtert wird. Die Mischinfektionserreger sind örtlich sehr versehiedener Art und bedingen dadurch lokale Vesschiedenheiten im Verlauf der Komplikationen.

Der Pfeiffersche Bacillus ist ein Sekundärerreger und als spezifisches Virus der Influenza abzulehnen. Ein Beweis für seine ätiologische Geltung ist nie erbracht worden; gegen ihn spricht sein Fehlen in den Krankheitsprodukten der Influenza und ihrer Komplikationen an vielen Orten, sein Auftreten lediglich in den als Komplikationen zu deutenden Prozessen, sein Vorkommen in gleicher Eigenschaft bei anderen, ätiologisch verschiedenen Krankheiten und schließlich das ganze epidemiologische Verhalten der Influenza. 


\section{Literaturverzeichnis.}

1. E. Adler und P. Kaznelson, Die Prager Pneumonieepidemie im Oktober 1918 und ihre Hämatologie. Med. Klinik. 1919. Nr.8.

2. K. Ahlborn, Einige klinische Beobachtungen bei der sog. ,spanischen Grippe". Münch. med. Woch. 1918. Nr.50.

3. A. Alexander, Zur Klinik der epidemischen Grippe, Med. Klinik. 1918. Nr, 42.

4. Derselbe, Zur Hämatologie der spanischen Grippe; D. mell. Woch, 1918. Nr. 45 .

5. Derselbe, Die ansteckende, hämorrhagische Pneumonie. Med. Klinik. 1918. Nr. 50.

6. v. Angerer, Ein filtrierbarer Erreger der Grippe. Münch. med. Woch. 1918. Nr, 46.

7. Arneth, Über Grippebeobachtungen im Felde. Med. Klinik. 1919. Nr. 7.

8. E. Becher, Zur Klinik der Influenza 1918. Ebenda. 1918. Nr.41.

9. K. Beckmann, Über Darmblutungen nach epidemischer Grippe. D. med. Woch. 1918. Nr, 40.

10. W. Berblinger, Komplikationen bei Grippe. Münch. med. Woch. 1918. Nr. 52.

11. G. v. Bergmann, Die spanische Krankheit ist Influenza vera. D. med. Woch, 1918. Nr. 34. Nr. 28.

12. G. Bernhardt, Zur Ätiologie der Grippe von 1918. Med. Klinik. 1918.

13. A. Binder und H. Prell, Studien zur Ätiologie der Influenza. Münch. med. Woch. 1918. Nr. 50.

14. Dieselben, Studien zur Ätiologie der Influenza. Ebenda. 1918, Nr. 52.

15. K. Bley, Die „Spanische Krankheit" in der Franenklinik. Ebenda. 1919. Nr. 11.

16. Bochalli, Grippe und Tuberkulose. Ebenda. 1919. Nr. 12.

17. Bon hoff, Sitzungsbericht des ärztl. Vereins zu Marburg vom 18, XII. 18. Ebenda. 1919. Nr. 6.

18. M. Borst, Pathologisch-anatomische Beobachtungen zur spanischen Grippe 1918. Ebenda. 1918. Nr. 48.

19. W. Brasch, Über die influenzaartige Epidemie im Juli 1918. Ebenia. 1918. Nr. 30.

20. O. Busse, Zur pathologischen Anatomie der Grippe. Ebenda. 1919. Nr. 5.

21. J. Citron, Spanische Grippe. Berl. klin. Woch. 1918. Nr. 33.

22. Derselbe, Spanische Grippe. Ebenda. 1918. Nr. 43. 
23. G. Deusch, Grippe und Lungentuberkulose. Münch, med. Woch. 1919. Nr. 17.

24. R. Deussing, Ủber die Bedeutung sekundärer Infektionen für die Erkrankungen der Lungen und der Pleura während der Influenzapandemie 1918: Med. Klinik. 1918. Nr. 39.

25. Derselbe, Influenza bei Diphtherie und Scharlach. Ebenda. 1919. Nr. 10

26. A. Dietrich, Pathologisch-anatomische Beobachtungen iuber Influenza. im Felde. Minch. med. Woch. 1918. Nr. 34.

27. A. Döblin, Nasenbluten bei der Influenza. Med. Klinik. 1919. Nr.6.

28. Dünner und Pupke, Influenzanephritis und Kriegsnephritis. Berl. klin. Woch. 1919. Nr. 3.

29. Federschmidt, Nürnbergs Grippeepidemie. Münch. med. Woch. 1919. Nr. 13.

30. Fejes, Die Ätiologie der Influenza. D. med. Woch. 1919. Nr. 24.

31. A. Fischer, Warum sterben an der Grippeinfektion gerade die Kräftigsten? Münch. med. Woch. 1918. Nr.46.

32. B. Fischer, Sitzungsbericht des ärztl. Vereins Frankfurt a. M. 2. IX. 18. Med. Klinik. 1918. Nr. 39.

33. E. Fraenkel, Sitzungsbericht des ärtl, Vereins Hamburg vom 7. I. 19. D. med. Woch. 1919. Nr. 14.

34. E. Fränkel, Bakteriologische Befunde bei Grippe. Ebenda. 1918. Nr. 51.

35. E. Friedberger, Sitzungsbericht des Greifswalder med. Vereins vom 5. V1I. 18. Ebenda. 1918. Nr. 45.

36. E. Fried berger und P. Konitzer, Zur Ätiologie derderzeitigen Influenzaepidemie. Med. Klinik. 1919. Nr. 5.

37. Fromme, Zur Influenzacpidemie. D. med. Woch. 1918. Nr, 51.

38. Th. Fürst, Ưber die Agglutination von Influenzabazillen durch Krankenserum zur Differentialdiagnose. Münch. med. Woch. 1919. Nr. 3.

39. E. Galewsky, Über Haarausfall nach Grippe. Ebenda. 1919. Nr. 14.

40. E. Goldschmid, Anatomische Befunde hei der Influenzaepidemie im Sommer 1918. Ebenda. 1918. Nr. 40.

41. A. Gottstein, Zur Grippeepidemie. D. med. Woch. 1918, Nr.41.

42. Grabisch, Zur Frage, warum an der Grippeinfektion gerade die kräftigsten Individuen sterben. Mïnch.'med. Woch. 1919. Nr.9

43. K. Grasmann, Über die Grippeepidemie an der Front in den Sommermonaten 1918. Ebenda. 1918, Nr. 51.

44. H. Grau, Beobachtungen 7ur Influenzafrage. Ebenda. 1918. Nr.49.

45. R. Grote, Serumbehandlung bei bösartiger Influenza. D. med. Woch. 1918. Nr. 50.

46. G. B. Gruber und A. Schädel, Zur pathologischen Anatomie und zur Bakteriologie der influenzaartigen Fpidemje im Juli 1918. Miinch. med. Woch. 1918. Nr. 33.

47. J. Jacob, Thrombose und variolaähnliches Exanthem bei Grippe. D. med. Woch. 1919: Nr. 1.

48. N. Haase und Wohlrabe, Ưber das Blutbild bei Influenza. Ebenda. 1918. $\cdot$ Nr. 50 .

49. E. Hannemann, Anatomische Befunde bei Grippe. Ebenda. 1919. Nr.9.

50. Hansen, Grippe und Salvarsan. Mïnch. need. Woch. 1918. Nr.49. 
5l. C. Hart, Die pathologische Anatomie und Bakteriologie der Influeezaepidemie 1918. Med. Klinik. 1918. Nr.40.

52. J. Heising, Influenza und Nephritis. D. med. Woch. 1919. Nr. I. $\mathrm{Nr} .5$.

53. G. Herzog, Zur Bakteriologie der Influenza. Mïnch. med. Woch. 1919.

54. W. Hease, Die sogenannte spanische Krankheit. Ebenda. 1918. Nr. 30.

55. C. Hirsch, Die Grippeerscheinungen im Gebiete des Ohres und der oberen Luftwege. D. med. Woch. 1919. Nr. 1.

56. Hirschbruch, Über die ansteckende Lungenentzündung. (Spanische Krankheit.) Ebenda. 1918. Nr. 34.

57. H. v. Hoesslin, Bemerkungen zum bakteriologischen und klinisohen Charakter der diesjährigen Grippeepidemie. Mïnch. med. Woch. 1918. Nr.41.

58. A, Hoffmann und E. Keuper, Zur Influenzaepidemie, D. med, Woch. 1919. Nr, 4.

59. Hohlweg, Zur Pathologie und Therapie der Grippe. Mïnch. med. Woch. 1919. Nr. 5.

60. G. Hoppe - Seyler, Zum Krankheitsbild und zur Behandlung der Grippe. D. med. Woch. 1919 . Nr. 3.

61. P. Hübs e hmann, Über die derzeitige Influenza und ihre Komplikationen. Münch. med. Woch. 1918. Nr. 44.

62. K. Hundeshagen, Zur Züchtung des Influenzabazillus. D. med. Wock. 1918. Nr. 43.

63. G. Jochmann, Lehrbuch der Infektionskrankheiten. (1914).

64. Kantorowicz, Nasenblutungen bei Influenza, Med. Klinik. 1919: Nr. I.

65. W. v. Kaufmann, Verhalten der Sera von an „Spanischer Krankheit" Leidenden zur Meineckeschen Lipoidbindungsreaktion. Ebenda. 1918. Nr. 33.

66. Kisskalt, Sitzungsbericht der med. Gesellschaft Kiel vom 28. XI. 18. Ebenda. 1918 . Nr. 52.

67. F. Klewitz, Zur Klinik der infektiösen Grippe. Ebenda. 1919. Nr.9.

68. A. V. Knack, Das Verhalten der Nieren bei der Grippe. Ebenda. 1918. Nr. 37.

69. König, Sitzungsbericht des ärztl. Bezirksvereins Würzburg vom 3. XII. 1918. Minch. med. Woch. 1918. Nr.52.

70. Koepohen, Symptomatologie der influenzaähnlichen, sog. spanischen Krankheit. D. med. Woch. 1918. Nr. 34.

71. Kolle und Hetsch. Die experimentelle Babteriologie und die Infektionskrankheiten. 4. Aufl. 1916.

72. R. Korbsch, Weitere Befunde von Influenzabazillen bei der diesjährigen Grippeepidemie. Med. Klinik. 1918. Nr. 44.

73. Derselbe, Zur Bakteriologie der Influenzaepidemie. Ebenda. 1919. Nr. 3.

74. Kosse1, Sitzungsbericht des naturhistorisch-medizinischen Vereins Heidelberg vom 16. VII, 18. D. med. Woch. 1918. Nr. 49.

75. H. Kronberger; Zur Hämatologie und Bakteriologie der Grippe. Ebenda. 1919. Nr.9.

76. Kroner, Influenzaähnliche Erkrankungen. Berl. klin. Woch. 1918. Nr, 27.

77. Kruse, Sitzungabericht der med. Gesellschaft Leipzig rom 23. VII. 18. Münch. med. Woch. 1918. Nr. 44.

78. R. Lämpe, Über die spanische Grippe. Med. Klinik. 1918. Nr.35. 
79. Br. Leichtentritt, Bakteriologische Befunde bei der Influenzaepidemio. D. med. Woch. 1918. Nr. 61.

80. Leschke, Ätiologie der Grippe. Berl. klin. Woch. 1919. Nr. 1.

81. M. Levy, Hämatologisches zur Grippeepidemie, D. med. Woch. 1918. Nr. 35.

82. A. Löwenstein, Über einen Fall von metastatischer Streptokokkeneiterung im Auge nach spanischer Grippe. Münch. med. Woch. 1918. Nr. 45.

83. W. Loewenthal, Bakteriologische Untersuchungen bei der diesjährigen Grippeepidemie. Berl. klin. Woch. 1918.' Nr.49.

84. Mahlo, Sitzungsbericht des ärztl. Verein Hamburg vom 7. I. 19. Med. Klinik. 1919. Nr. 13.

85. Mandelbaum, Epidemiologische und bakteriologische Untersuchungen iiber die pandemische Influenza. Münch. med. Woch. 1918. Nr. 30.

86. F. Marchand, Über die pathol.-anatomischen Befunde bei der diesjährigen Influenzaepidemie. Ebenda. 1919. Nr.5.

87. K. Mayer, Über Schutzkörpermangel bei Grippe nach Beobachtungen ïber die Grippe 1918 unter den deutschen Truppenteilen in Konstantinopel. Ebenda. 1919. Nr. 17.

88. F. Meyer, Die Behandlung der Grippepneumonie. D: med. Woch. 1919. Nr. 7.

89. S. Meyer, Über stenosierende pseudomembranöse Entzïndung der Luftwege bei epidemischer Grippe. Ebenda, 1919. Nr. 2.

90. F. Neufeld und P. Papamarku, Zur Bakteriologie der diesjährigen Influenzaepidemie. Ebenda. 1918. Nr.43.

91. L. Nürnberger und G. Kalli woda, Über die differentialdiagnostigche Abgrenzung von Grippe und Kindbettfieber auf Grund bakteriologischer und hämatologischer Untersuchungen. Münch. med. Woch. 1919. Nr. 11.

92. Oberndorfer, Über die pathologische Anatomie der influenzaartigen Epidemie im Juli 1918. Ebenda. 1918. Nr. 30.

93. H. Oeller, Zur Ätiologie der Influenza. Med. Klinik. 1918. Nr.44.

94. Derselbe, Kritische Studien zum Influenzaproblem. Mikch. med. Woch. 1918. Nr. 44.

95. Olsen, Zur Bakteriologie der Influenza. Ebenda. 1919. Nr.9.

96. O. Orth, Thrombosen bei der spanischen Krankheit. D. med. Woch. 1918. Nr. 47.

97. Pelz, Truppenärztliche Beobachtungen über die sog. spanische Grippe. Elbenda. 1918. Nr. 40.

98. R. Pfeiffer, Sitzungsbericht der schlesischen Gesellschaft für vaterl. Kultur (Med. Sektion) vom 8. XI. 18. Med. Klinik. 1919. Nr. 3.

99. Pöppelmann, Zur Ätiologie der Grippe. D. med. Woch. 1919. Nr. 14. 100. Rickmann, Grippe und Lungentuberkulose. Ebenda. 1919. Nr. 2.

101. S. Rosenbaum, Über die Infektiosität der Grippepneumonien. Münch. med. Woch. 1919. Nr.7.

102. G. Rosenow, Das Blutbild bei der Grippe:; Med. Klinik. 1918, Nr. 30. Nr. 3.

103. K. Scheer, Zur Serodiagnostik der Grippe. Minch. med. Woch. 1919. 
104. R. Scheller, Die Gruppe der hämoglobinophilen Bakterien. A.Influenza im Handbuch der pathogenen Mikroorganismen von Kolle und Wassermann. 2. Aufl, Bd. V.

105. F. Sobesinger, Eine neue Infektionskrankheit. D. med. Woch. 1918. Nr. 28.

106. O. Schiemann, Zur Influenzadiagnose, Med, Klinik. 1918. Nr.39.

107. Schmieden, Über die chirurgischen Erscheinungsformen der Grippe. Mïnch. med. Woch. 1919. Nr.9.

108. G. Schmorl, Pathol.-anatomische Beobachtungen bei der jetzt herrschenden Influenzaepidemie. D. med. Woch. 1918. Nr. 34.

109. H. Schöppler, Pathol.-anatomische und bakteriologische Befunde bei dem sog. Morbus ibericus 1918. Münch. med. Woch. 1918. Nr. 32.

110. Schott, Influenza und Herzerkrankungen. Ebenda. 1919. Nr. 10.

111. Schwermann, Beitrag zur Pathologie der Spanischen Krankheit. Med. Klinik. 1918. Nr.42.

112. H. Selter, Zur Ätiologie der Influenza. D. med. Woch. 1918. Nr. 34.

113. H. Siegm und, Pathol.-anatomische Befunde bei der Influenzaepidemie im Sommer 1918. Med. Klinik. 1919. Nr.4.

114. Silbermann, Zur Ätiologie der spanischen Krankheit. D. med. Woch. 1918. Nr.45.

115. M. Simmonds, Zur Pathologie der diesjährigen Grippe. Münch. med. Woch, 1918. Nr. 32.

116. G. Sobernheim und G. Nowakovic, Beitrag zur Bakteriologie der Influenza. Ebenda. 1918, Nr. 49.

117. E. Stettner, Über Stenosen der Luftwege bei epidemischer Grippe im frühen Kindesalter. Ebenda. 1918. Nr. 32.

118. A. v. Strüm pell. Lehrbuch dér speziellen Pathologie und Therapie der inneren Krankheiten. 1909.

119. Derselbe, Über Influenza. Münch. med. Woch. 1918. Nr.40.

120. Uhlenhuth, Zur Bakteriologie der Influenza 1918. Mfed. Klinili. 1918. Nr. 32 .

121. F. Wachter, Erfahrungen bei der Influenzaepidemie. D. med. Woch. 1918. Nr. 43 . Nr. 45 .

122. F. Witte, Zur Behandlung der Grippe mit Kollargol. Ebbenda. 1918.

123. Zeissler, Sitzungsbericht des ärztlichen Vereins Hamburg vom 21. I, 19. Ebenda. 1919. Nr. 16. 